\title{
Genome-wide analysis of differentially expressed profiles of mRNAs, IncRNAs and circRNAs in chickens during Eimeria necatrix infection
}

Xian-Cheng Fan ${ }^{1,2+}{ }^{\text {, Ting-Li Liu }}{ }^{1,3 \dagger}{ }^{+}$Yi Wang ${ }^{1}$, Xue-Mei Wu${ }^{1}$, Yu-Xin Wang ${ }^{1}$, Peng Lai ${ }^{1}$, Jun-Ke Song ${ }^{1}$ and Guang-Hui Zhao ${ }^{*}$

\begin{abstract}
Background: Eimeria necatrix, the most highly pathogenic coccidian in chicken small intestines, can cause high morbidity and mortality in susceptible birds and devastating economic losses in poultry production, but the underlying molecular mechanisms in interaction between chicken and E. necatrix are not entirely revealed. Accumulating evidence shows that the long-non-coding RNAs (IncRNAs) and circular RNAs (circRNAs) are key regulators in various infectious diseases. However, the expression profiles and roles of these two non-coding RNAs (ncRNAs) during E. necatrix infection are still unclear.

Methods: The expression profiles of mRNAs, IncRNAs and circRNAs in mid-segments of chicken small intestines at $108 \mathrm{~h}$ post-infection (pi) with E. necatrix were analyzed by using the RNA-seq technique.

Results: After strict filtering of raw data, we putatively identified 49,183 mRNAs, 818 IncRNAs and 4153 circRNAs. The obtained IncRNAs were classified into four types, including 228 (27.87\%) intergenic, 67 (8.19\%) intronic, 166 (20.29\%) anti-sense and 357 (43.64\%) sense-overlapping IncRNAs; of these, 571 were found to be novel. Five types were also predicted for putative circRNAs, including 180 exonic, 54 intronic, 113 antisense, 109 intergenic and 3697 senseoverlapping circRNAs. Eimeria necatrix infection significantly altered the expression of 1543 mRNAs (707 upregulated and 836 downregulated), 95 IncRNAs (49 upregulated and 46 downregulated) and 13 circRNAs (9 upregulated and 4 downregulated). Target predictions revealed that 38 aberrantly expressed IncRNAs would cis-regulate 73 mRNAs, and 1453 mRNAs could be trans-regulated by 87 differentially regulated IncRNAs. Additionally, 109 potential sponging miRNAs were also identified for 9 circRNAs. GO and KEGG enrichment analysis of target mRNAs for IncRNAs, and sponging miRNA targets and source genes for circRNAs identified associations of both IncRNAs and circRNAs with host immune defense and pathogenesis during E. necatrix infection.
\end{abstract}

Conclusions: To the best of our knowledge, the present study provides the first genome-wide analysis of mRNAs, IncRNAs and circRNAs in chicken small intestines infected with E. necatrix. The obtained data will offer novel clues for exploring the interaction mechanisms between chickens and Eimeria spp.

Keywords: Eimeria necatrix, mRNAs, IncRNAs, circRNAs, Chicken small intestine, Expression profile

\footnotetext{
*Correspondence: zgh083@nwsuaf.edu.cn

${ }^{\dagger}$ Xian-Cheng Fan and Ting-Li Liu are equal contributors

${ }^{1}$ Department of Parasitology, College of Veterinary Medicine, Northwest

A\&F University, Yangling 712100, China

Full list of author information is available at the end of the article
}

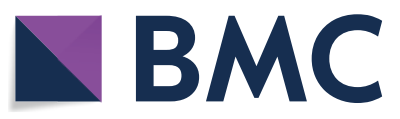

(c) The Author(s) 2020. This article is licensed under a Creative Commons Attribution 4.0 International License, which permits use, sharing, adaptation, distribution and reproduction in any medium or format, as long as you give appropriate credit to the original author(s) and the source, provide a link to the Creative Commons licence, and indicate if changes were made. The images or other third party material in this article are included in the article's Creative Commons licence, unless indicated otherwise in a credit line to the material. If material is not included in the article's Creative Commons licence and your intended use is not permitted by statutory regulation or exceeds the permitted use, you will need to obtain permission directly from the copyright holder. To view a copy of this licence, visit http://creativeco mmons.org/licenses/by/4.0/. The Creative Commons Public Domain Dedication waiver (http://creativecommons.org/publicdomain/ zero/1.0/) applies to the data made available in this article, unless otherwise stated in a credit line to the data. 


\section{Background}

Chicken coccidiosis, caused by Eimeria spp., is one of the most common diseases in broilers and laying hens, seriously affecting weight gains and leading to death of birds $[1,2]$. Severely infected chickens present typical clinical symptoms such as anorexia, dehydration, diarrhea with mucus and/or blood [3, 4]. The economic losses caused by chicken coccidiosis were estimated to over 3 billion USD per year worldwide and approximately 30-60 million USD have been spent to control this disease annually in China [5-7]. Currently, the prophylactic use of anticoccidial drugs or vaccines of precocious, attenuated parasites, and wild type vaccine formulations are common strategies to control chicken coccidiosis in clinic [8-11]. However, coccidiostats were challenged due to increasing evidence of drug resistance and residues $[10,12]$. The vaccination was also hampered by limited production capacity, costs and the complexity of cross-protection for different Eimeria species [2,13-15]. Therefore, development of novel strategies for controlling coccidiosis is urgently needed.

In recent years, finding key molecules in the host-parasite interaction is becoming an alternative approach for analyzing pathogenic mechanisms and exploring novel targets for developing drugs and vaccine candidates to control parasitic diseases [16-20]. Using the complementary DNA (cDNA) microarray technique, a great number of differentially regulated mRNA molecules in chicken intestines have been identified after infections with E. tenella [4, 21], E. acervulina [21-24] and E. maxima $[9,21,22]$. Functional analysis suggests that these differentially expressed genes would be associated with immune response/defense, apoptosis/cell death and differentiation, signal transduction, physiological development and function and extracellular matrix (ECM) $[4,9$, 21-24]. However, different biological functions within the category "physiological development and function" after primary infection with these three Eimeria species were also predicted. For example, some differentially expressed transcripts were enriched in "connective tissue development and function" and "digestive system development and function" after E. tenella infection, while some mRNAs were enriched in "endocrine system development and function" and "hepatic system development and function" after E. acervulina infection. The biofunctions of "renal and urological system development and function" and "reproductive system development and function" were uniquely identified after E. maxima infection [21]. These findings suggest differences in the interaction between Eimeria spp. and chickens.

Recently, two novel "star non-coding RNAs (ncRNAs)", namely long non-coding RNA (lncRNA) and circular RNA (circRNA), have been reported to play pivotal role in the interaction between hosts and bacteria [25, 26], viruses [27-30] and parasites [31-33]. For example, using the RNA-seq technique, the expression profiles of mRNAs, lncRNAs and circRNAs of tracheal tissues during Cryptosporidium baileyi infection were studied, and functional analysis of these differentially expressed RNAs were related to the immune system process, immune response and leukocyte activation, tight junction and glycerolipid metabolism, suggesting the important role of these RNAs in interaction between chickens and C. baileyi [33].

Of seven Eimeria species (E. acervulina, E. brunetti, E. maxima, E. mitis, E. necatrix, E. praecox and E. tenella) $[34,35]$, E. necatrix is the most highly pathogenic coccidium in small intestines of chickens, and can cause high mortality in susceptible birds [36], especially in floorreared chickens older than 8 weeks-old $[37,38]$. Currently, most studies were mainly focused on exploration of etiological biology and pathogenic features of E. necatrix $[15,39]$. In the present study, the expression profiles of mRNAs, lncRNAs and circRNAs were systemically studied in chickens infected with $E$. necatrix using the RNA-seq technique.

\section{Methods}

\section{Eimeria necatrix infection model}

Eimeria necatrix used in the present study was isolated from the small intestines of sick chickens presented to the clinic (Baoji, Shaanxi, China), purified and propagated by using the single-oocyst method described previously $[40,41]$, and identified by using the speciesspecific PCR and sequencing (data not shown).The purified oocysts were passaged in 10-day-old Hy-line variety white specific-pathogen-free (SPF) chickens under a specific pathogen- and coccidia-free environment, and fresh fecal samples were collected for purifying oocysts using the salt-floatation technique. The purified oocysts were sporulated at $28{ }^{\circ} \mathrm{C}$ and oocysts with a sporulation rate $>95 \%$ were stored in potassium dichromate solution at 4 ${ }^{\circ} \mathrm{C}$ for further study. All sporulated oocysts were washed with sterile distilled water and treated with $5 \%(\mathrm{v} / \mathrm{v})$ sodium hypochlorite solution in an ice-bath for 15-20 min before being used in infection studies [42].

One-day-old hatched Hy-line variety white cockerels were purchased from the Giant Long Company (Yangling, Shaanxi, China) and divided into the control (N) and experimental (S) groups with 30 chickens in each group. After being reared for 10 days with sterile water and fed without anti-coccidial drugs and antibiotics, in separated coccidia-free isolation cages under the specific pathogen and coccidia-free environment, each cockerel in group $\mathrm{S}$ was orally infected with 8000 sporulated 
oocysts, while the same volume of phosphate-buffered saline (PBS, pH 7.4) were orally given to cockerels in group N. Following infection, fecal samples and the midintestinal scrapings from the small intestines of three cockerels in both groups were examined daily for 4 days.

\section{Collection and preparation of tissue samples}

At $108 \mathrm{~h}$ post-infection (pi), three cockerels of each group were randomly selected and euthanized by cervical dislocation. The mid-segment of the small intestine from each selected cockerel was excised, opened longitudinally and washed with nuclease-free PBS to remove intestinal contents and mucus. Then, the treated intestinal tissues were quick-frozen in liquid nitrogen.

\section{RNA extraction, library preparation and RNA sequencing}

Total RNA of each frozen mid-intestinal segment was extracted using the mirVana ${ }^{\mathrm{TM}}$ miRNA Isolation Kit (Ambion, Austin, TX, USA) according to the manufacturer's instructions and stored at $-70{ }^{\circ} \mathrm{C}$. RNA integrity was evaluated using the Agilent 2100 Bioanalyzer (Agilent, Santa Clara, CA, USA), and samples with an RNA integrity number (RIN) value of $\geq 7$ were subjected to subsequent sequencing analysis. Then, the RNA library was constructed with RNA samples of $1 \mu \mathrm{g}$ using the TruSeq Standard Total RNA with Ribo-Zero Gold in accordance with previous studies [43, 44]. RNA-seq was performed on an Illumina $\mathrm{HisSeq}^{\mathrm{TM}} 2500$ instrument generating $150 \mathrm{bp} / 125 \mathrm{bp}$ paired-end reads. All these procedures were carried out in the laboratory of Shanghai OeBiotech Co. (Shanghai, China).

\section{Quality control and reference genome mapping}

The raw data obtained were deposited into the Sequence Read Archive (SRA) within NCBI, with the accession numbers SRR9331386 and SRR9331387. The raw data were processed using the software Trimmomatic [45]. To obtain clean reads, the reads containing adaptors, lowquality reads and bases at 5 '- and 3'-ends were removed. Meanwhile, the Q30 and GC contents of the clean reads were calculated to assess the quality of these reads. Then the clean reads were mapped into the Gallus gallus reference genome (ftp://ftp.ncbi.nlm.nih.gov/genom es/all/GCF/000/002/315/GCF_000002315.5_GRCg6 a/GCF_000002315.5_GRCg6a_genomic.fna.gz) using hisat2 (2.2.1.0) software to obtain information of locations and sequence characteristics of the clean reads.

\section{Identification of IncRNAs and circRNAs from the RNA-seq dataset}

The mapped clean reads were assembled based on the probabilistic model by using the software Stringtie2 (1.3.3b). Because of alternative splicing, a gene can produce isoforms with different lengths. To reduce false positives and increase the accuracy of prediction, in the present study, the known ncRNAs in the sequencing data were obtained directly, while the splicing transcripts with exons $\geq 2$ and lengths $>200$ bp were screened for coding potential analysis by using the software programs coding potential calculator (CPC, 0.9-r2), coding-non-coding index (CNCI, 1.0), Pfam (1.2) protein domain and predictor of long non-coding RNAs and messenger RNAs based on an improved $k$-mer scheme (PLEK1.2) [46], and the transcripts without coding potential by all four tools were predicted to be IncRNAs. The characters of identified lncRNA were then analyzed, including length distribution, GC content frequency distribution and type and number of exons.

Because chicken is not a model organism, the circRNA of the present study was de novo predicted using the CIRI (v2.0.3) software [47]. The clean reads were first aligned with the G. gallus reference genome (ftp://ftp.ncbi.nlm. nih.gov/genomes/all/GCF/000/002/315/GCF_00000 2315.5_GRCg6a/GCF_000002315.5_GRCg6a_genom ic.fna.gz) to generate a SAM file. Then CIGAR values in the SAM file were calculated, and the paired chiastic clipping (PCC) signals in this file were also scanned. The junction reads were selected based on paired-end mapping and GT-AG splicing signals, and the clean reads including back-spliced signals and junction reads $>2$ were considered to be circRNAs.

\section{Differential expression analysis of mRNAs, IncRNAs and circRNAs}

The expression abundance of mRNAs and lncRNAs was calculated using bowtie (2.2.9) and eXpress (1.5.1) programs, and the fragments per kb per million reads (FPKM) [48] were measured to determine the expression level of mRNAs and lncRNAs in each sample. At the same time, the expression of circRNAs in each sample was calculated by spliced reads per million (RPM) [49]. Then, the DESeq (1.18.0) package within $\mathrm{R}$ (3.2.0) was used to analyze the inter-sample differential expression of predicted mRNAs, lncRNAs and circRNAs. For each sample, the counts of mRNAs, lncRNAs and circRNAs were normalized to compute the fold change (FC), and the negative binomial (NB) model was used to test the significance of the differences between the groups $\mathrm{S}$ and N.

\section{Target prediction of the differentially expressed IncRNAs and circRNAs}

The potential targets of the differentially expressed lncRNAs were predicted according to the co-expression correlation of lncRNAs and mRNAs by using Pearson's correlation analysis (Pearson's correlation coefficient 
$\geq 0.8$ and $P \leq 0.05)$ calculated with Pandas DataFrame using Python (3.6.5). Two regulatory modes, namely cis- and trans-acting, were included. The differentially expressed mRNAs $100 \mathrm{~kb}$ upstream and downstream of the differentially expressed lncRNAs were searched for prediction of cis targets, while the differentially expressed coding genes not located in the same chromosome were scanned for the trans-regulation targets of the differentially expressed lncRNAs, with the criterion of direct complementary base pairs $\geq 10$ and free energy $\leq-50$ $\mathrm{kcal} / \mathrm{mol}$.

CircRNAs have recently been identified to generally act as sponges through adsorbing miRNAs in bioprocesses of physiology and diseases [50-52], including infectious diseases. In the present study, the potential miRNA targets were predicted by using the miRanda (v3.3a) software [53], with the criterion of single-residue-pair match scores $\geq 150, \Delta G \leq-30 \mathrm{kcal} / \mathrm{mol}$ and demand strict $5^{\prime}$ seed pairing.

\section{Functional analysis of mRNAs, IncRNAs and circRNAs}

To predict the biological functions of mRNAs during $E$. necatrix infection, all differentially expressed mRNAs were submitted to the Gene Ontology (GO) (http:// geneontology.org/) database to be enriched with terms of three categories, i.e. cellular component (CC), biological process (BP), and molecular function (MF), and the pathways that these mRNAs would be involved in were also predicted by conducting Kyoto Encyclopedia of Genes and Genomes (KEGG) (http://www.genome.jp/ kegg/) pathway analysis. Since all differentially expressed mRNAs were predicted to be potential targets of differentially expressed lncRNAs, the functions of cis- and trans-acting targets of these lncRNAs were respectively annotated by using GO and KEGG pathway analysis. Additionally, the source genes and sponging miRNA targets of differentially expressed circRNAs were also enriched by performing GO and KEGG pathway analysis. The $P$-value was calculated within GO and KEGG pathway analysis, respectively, and a $P<0.05$ was considered to be significantly enriched.

\section{Quantitative real-time polymerase chain reaction (qRT-PCR) analysis}

Three mid-segments of chicken small intestines were collected from both $\mathrm{S}$ and $\mathrm{N}$ groups, and analyzed by qRTPCR to validate the RNA-seq data. The TRIzol reagent and chloroform-isopropyl alcohol method were used to isolate the total RNA from each tissue sample for the first-strand cDNA synthesis using the PrimeScript ${ }^{\mathrm{TM}}$ RT reagent Kit with gDNA Eraser (TaKaRa, Dalian, China) [54-56]. The qRT-PCR was performed using UltraSYBR Mixture (CWBIO, Beijing, China) on a Four-channel Real-time Fluorescence Quantitative PCR system (TL988; Tianlong, Shaanxi, China) using the primers listed in Additional file 1: Data S1. Three biological replicates were carried out in each qRT-PCR reaction and the glyceraldehyde-3-phosphate dehydrogenase (GAPDH) gene was included as an internal control in each reaction. The relative expression level of each gene was expressed as $2^{-\Delta \Delta C q}$.

\section{Statistical analysis}

The software Graphpad 7 (http://www.graphpad.com) was used to analyze the differences in expression levels of each selected gene between infected and control chicken samples; a $P$-value of $<0.05$ was considered to indicate statistically significant differences.

\section{Results}

Transcriptomic sequencing data analysis

In the present study, the Illumina sequencing generated 594.8 M raw reads from six chicken intestinal samples, and the number of original sequences for each sample ranged from $98.42 \mathrm{M}$ to $99.77 \mathrm{M}$. After removing adapter reads and low-quality reads, a total of 581,392,134 clean reads were retained, corresponding to $97.74 \%$ of raw sequences. The average GC content and Q30 of these clean reads were $48.35 \%$ and $95.54 \%$, respectively. Then, these clean reads were mapped to the latest G. gallus reference genome for transcript assembly and annotation. The percentage of the total mapped clean reads for each sample was $93.53-96.04 \%$, with 509,871,677 reads uniquely mapped to single loci and 41,537,429 reads mapped to multiple loci (Table 1). Then, the mapped

Table 1 The statistics of sequencing data

\begin{tabular}{|c|c|c|c|c|c|c|c|}
\hline Sample ID & Raw reads & No. of clean reads & No. of mapped reads (\%) & Q30 (\%) & GC (\%) & No. of multiple mapped (\%) & No. of uniquely mapped (\%) \\
\hline N1 & $99.31 \mathrm{M}$ & $97,281,202$ & $93,052,646(95.65)$ & 95.67 & 48.26 & $7,637,513(7.85)$ & $85,415,133(87.80)$ \\
\hline N2 & $99.27 \mathrm{M}$ & $97,187,802$ & $91,653,917(94.31)$ & 95.54 & 48.03 & $6,675,495(6.87)$ & $84,978,422(87.44)$ \\
\hline N3 & $99.39 \mathrm{M}$ & $96,653,394$ & $91,056,556$ (94.21) & 95.33 & 48.16 & $5,905,894(6.11)$ & $85,150,662$ (88.10) \\
\hline S1 & $98.42 \mathrm{M}$ & $96,673,328$ & $92,845,824(96.04)$ & 95.93 & 47.85 & $6,629,317(6.86)$ & $86,216,507$ (89.18) \\
\hline S2 & $99.77 \mathrm{M}$ & $97,421,742$ & $92,845,831(95.30)$ & 95.16 & 48.53 & $6,903,683(7.09)$ & $85,942,148$ (88.22) \\
\hline S3 & $98.64 \mathrm{M}$ & $96,174,666$ & $89,954,332(93.53)$ & 95.61 & 49.26 & $7,785,527(8.10)$ & $82,168,805(85.44)$ \\
\hline
\end{tabular}


clean reads were compared with reference transcripts by using the software cuffcompare (cufflinks-2.2.1), and 49,183 mRNAs were identified (Additional file 2: Data S2).

\section{Identification of IncRNAs and circRNAs in chicken intestinal tissues}

The mapped clean reads were assembled and compared with reference transcripts by using the software cuffcompare, and the transcripts with the characters of ' $\mathrm{i}$ ' (a transfrag falling entirely within a reference intron), ' $\mathrm{u}$ ' (unknown, intergenic transcript), ' $x$ ' (exonic overlap with reference on the opposite strand) and 'o' (generic exonic overlap with a reference transcript) were retained. Of them, the transcripts with the length $>200 \mathrm{bp}$ and exon count $\geq 2$ were selected and used for predicting the lncRNAs by screening coding potentials using the programs CPC, CNCI, Pfam and PLEK. Finally, a total of 818 lncRNAs were identified, including 247 known and 571 novel lncRNAs (Fig. 1a, Additional file 2: Data S2). The average
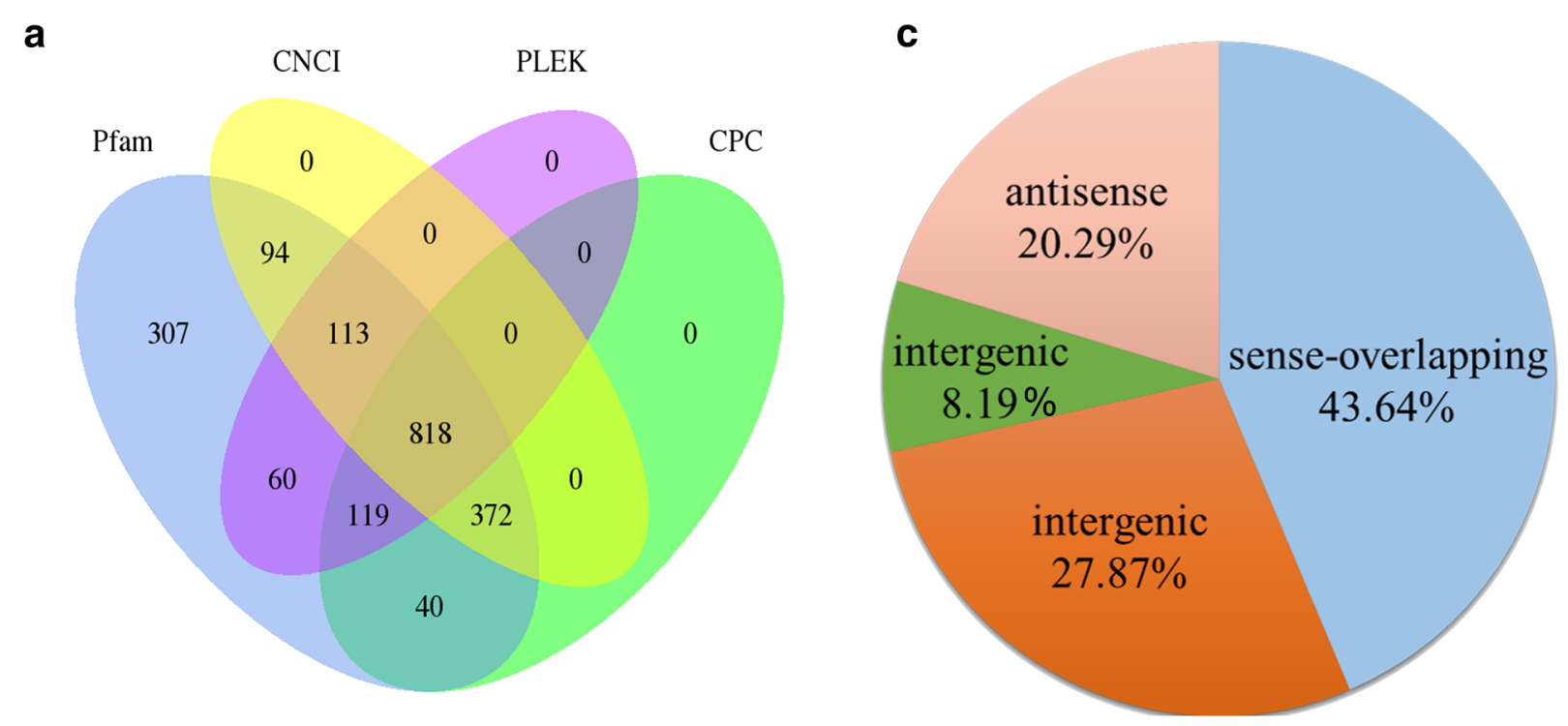

b

Exons per IncRNA

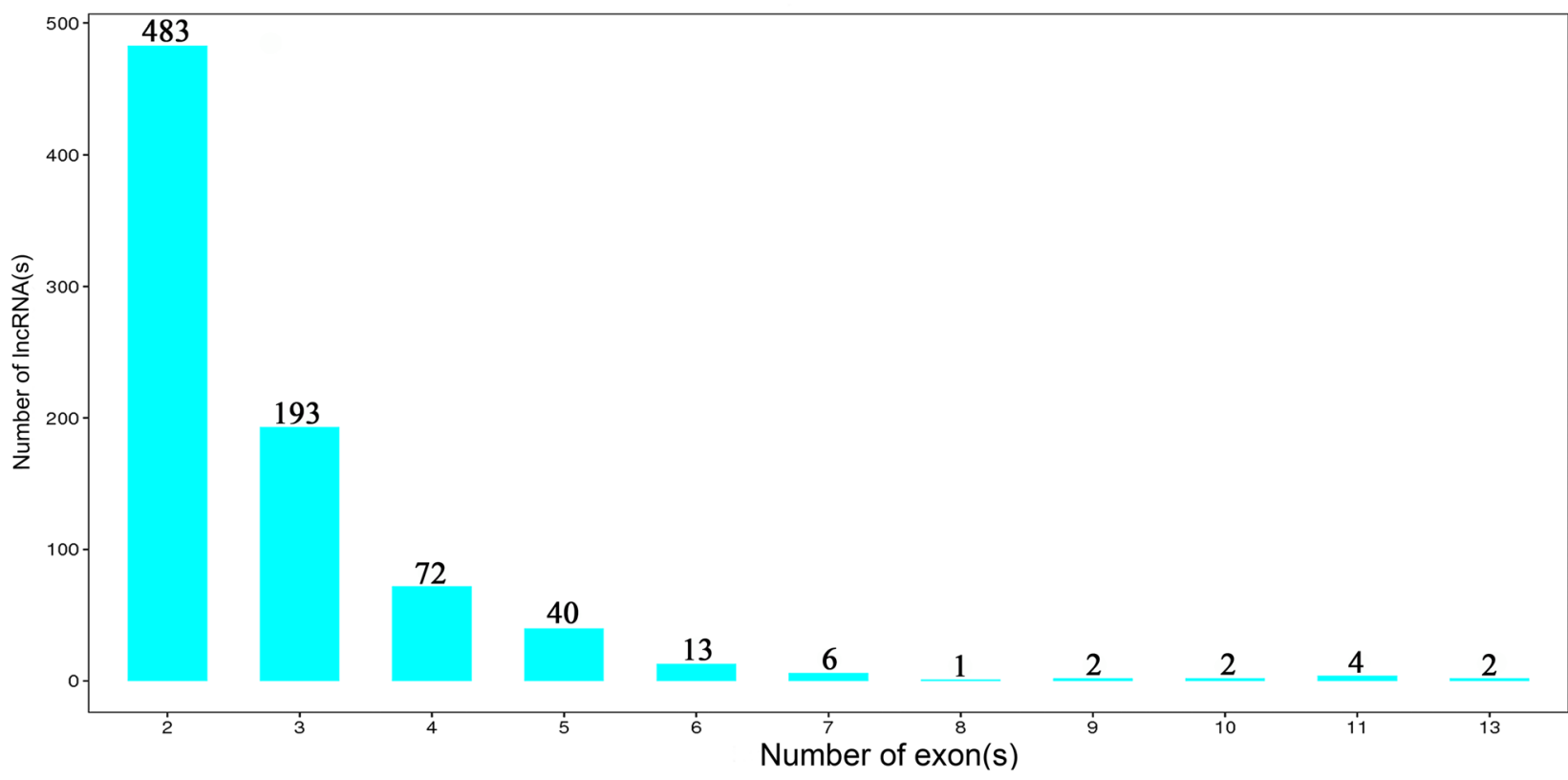

Fig. 1 Screening, exon numbers and classification of the candidate IncRNAs in chicken small intestines. a Venn diagram of coding potential analysis according to strict criteria. Four tools (CPC, CNCl, Pfam and PLEK) were used to analyze the coding potential of IncRNAs. b The distribution of exon numbers of IncRNAs. c Classification of the four subtypes of IncRNAs 

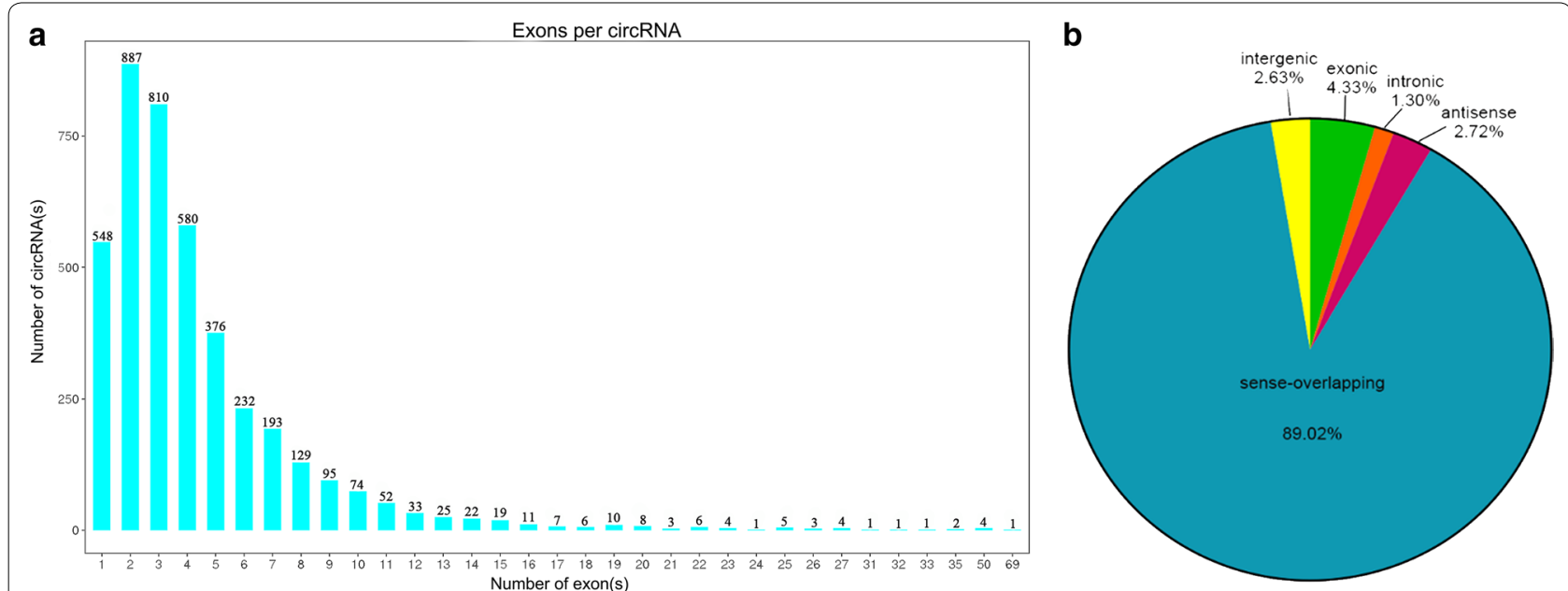

Fig. 2 Exon numbers and classification of the candidate circRNAs in chicken small intestines. a The distribution of exon numbers of circRNAs. b Classification of the five subtypes of circRNAs

length of these lncRNAs was $1151 \mathrm{bp}$, and most of them contained 2-5 exons (Fig. 1b, Additional file 3: Data S3). Further analysis showed that these IncRNAs were classified into four types, including 228 (27.87\%) intergenic, 67 (8.19\%) intronic, 166 (20.29\%) anti-sense, and 357 (43.64\%) sense-overlapping lncRNAs (Fig. 1c).

Additionally, 4153 circRNAs were predicted from the mapped clean reads in the present study (Additional file 2: Data S2). The length of these circRNAs ranged from 54 bp to $98,723 \mathrm{bp}$, with an average length of 3214 bp (Additional file 3: Data S3); the number of exons in these circRNA is shown in Fig. 2a. Of them, five types of circRNAs were predicted, including 180 exonic, 54 intronic, 113 antisense, 109 intergenic and 3697 senseoverlapping circRNAs (Fig. 2b).

\section{Differentially expressed profiles of mRNAs, IncRNAs and circRNAs}

To identify the mRNAs, lncRNAs and circRNAs associated with $E$. necatrix infection in chicken small intestines, the expression of these RNAs in chickens of the groups $\mathrm{N}$ and $\mathrm{S}$ was analyzed. Hierarchical clustering of the RNAs clearly showed the different patterns of mRNAs, lncRNAs and circRNAs between the groups $\mathrm{N}$ and $\mathrm{S}$ (Fig. 3ac). Compared with the group N, a total of 1543 mRNAs were differentially expressed (FC $>2, P<0.05$ and FDR $<0.05$ ), with 707 upregulated and 836 downregulated in the $\mathrm{S}$ group (Fig. 3d). Additionally, 95 lncRNAs (including 9 intergenic, 4 intronic, 12 anti-sense and 12 sense-overlapping lncRNAs) and 13 circRNAs (including 10 senseoverlapping and 3 exonic circRNAs) were differentially expressed (FC $>2, P<0.05$ and FDR $<0.05$ ) between the two groups. Of these, 49 lncRNAs were upregulated and
46 lncRNAs were downregulated in the S group (Fig. 3e), while 9 and 4 circRNAs were upregulated and downregulated, respectively, in this group (Fig. 3f).

\section{Validation of differentially regulated mRNAs, IncRNAs and circRNAs}

To verify the RNA-seq data, qRT-PCRs were performed to determine the expression levels of ten mRNAs (five upregulated and five downregulated), ten lncRNAs (five upregulated and five downregulated) and six circRNAs (five upregulated and one downregulated) that were randomly selected from the RNA-seq data. The expression patterns of these genes were consistent with RNA-seq (Fig. 4), confirming the high reliability and reproducibility of the RNA-seq analysis for identifying genes associated with $E$. necatrix infection.

\section{Co-expression analysis and target prediction}

Growing evidence has indicated that lncRNA is an important competing endogenous RNA (ceRNA) in multiple physiological and disease processes through cis- and trans-regulating expression of their target mRNAs [57-59]. In the present study, the co-expression networks between the significantly differentially regulated mRNAs and lncRNAs were re-constructed. Based on expression correlation coefficients (Pearson's correlation coefficient $\geq 0.8$ and $P \leq 0.05$ ), a total of 95 lncRNAs were co-expressed with 1543 mRNAs, comprising 37,134 relationships (Additional file 4: Data S4). Multiple mRNAs could be regulated by one lncRNA, and one mRNA could be regulated by several lncRNAs (Fig. 5), implying a complex regulation between differentially regulated lncRNAs and mRNAs. 

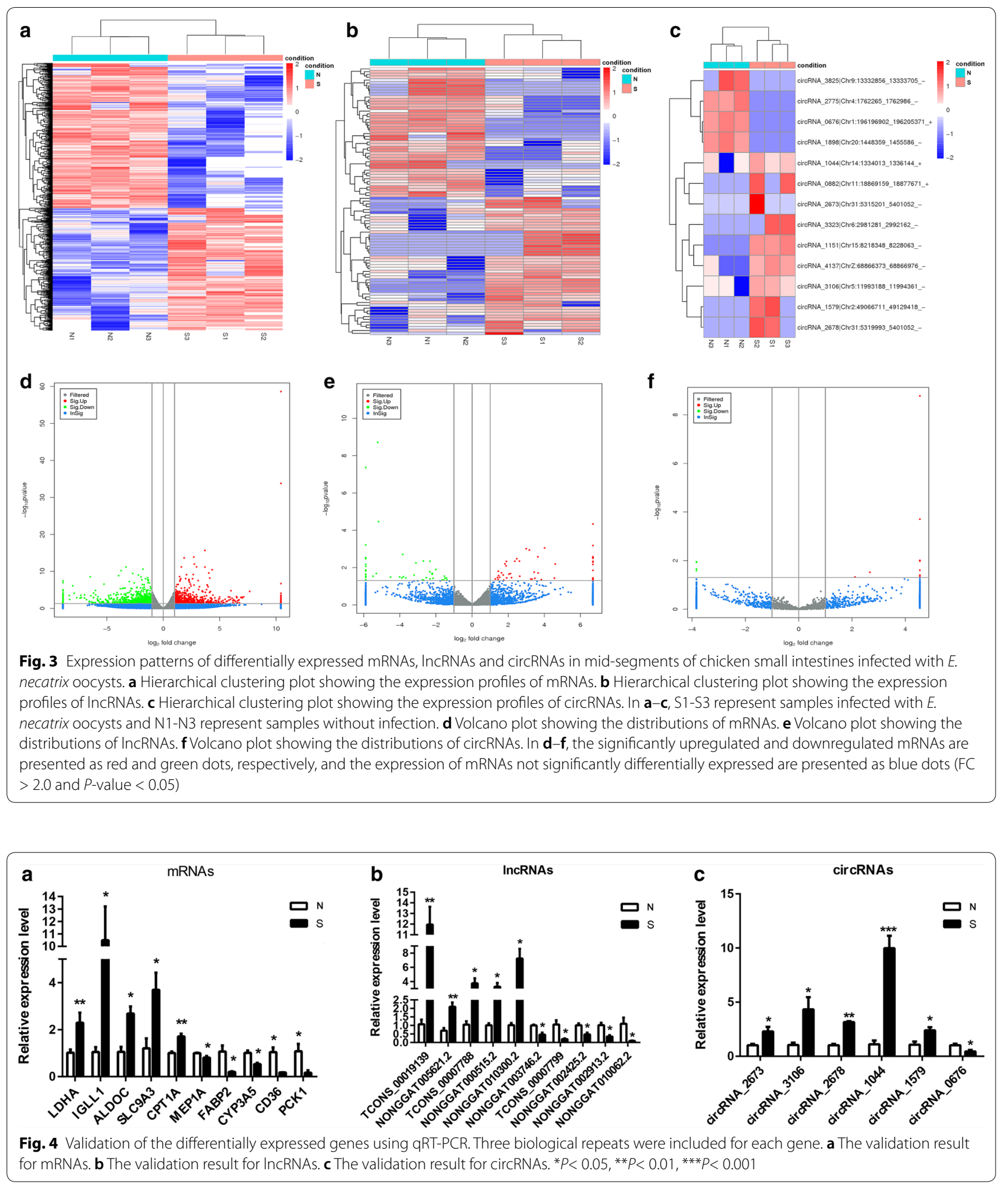

To predict the potential cis-targets of significantly differentially expressed lncRNAs in the present study, the significantly differentially co-expressed mRNAs 100 $\mathrm{kb}$ upstream and downstream were searched, and 73
mRNAs would be cis-regulated by 38 lncRNAs (Additional file 5: Data S5). For prediction of trans-targets of these differentially regulated lncRNAs, the significantly differentially co-expressed mRNAs located on different 


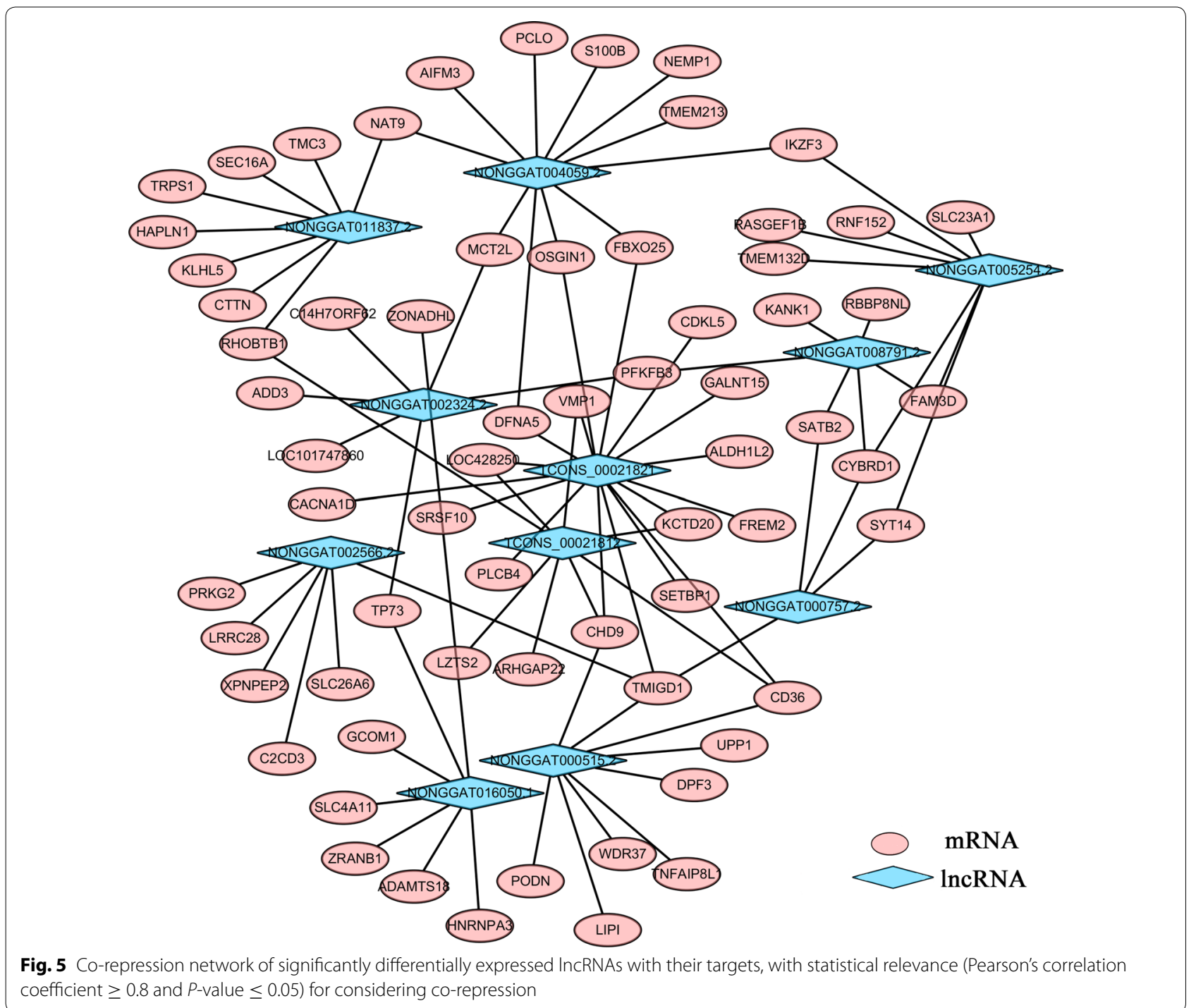

chromosomes were screened, and 1453 mRNAs were identified to be potential trans-targets of 87 lncRNAs (Additional file 5: Data S5) with the criteria of direct complementary base pairs $\geq 10$ and free energy $\leq-50$ $\mathrm{kcal} / \mathrm{mol}$.

Recent studies evidenced that circRNAs commonly function as miRNA sponges to play significant regulatory roles in several diseases [60-64]. Herein, the potential miRNA targets of 9 significantly differentially expressed circRNAs were predicted based on complementary base pairing, with 109 miRNAs identified (Additional file 6: Data S6). The circRNAmiRNA-mRNA network showed that the regulatory relationships between circRNAs, miRNAs and target mRNAs were complex (Fig. 6).

\section{Functional annotation of differentially regulated IncRNAs} and circRNAs

To reveal the role of lncRNAs during E. necatrix infection, the potential targets of the differentially regulated lncRNA in the present study were submitted to GO and KEGG databases. A total of $1678(P<0.05)$ GO terms were enriched (Additional file 7: Data S7); the top 10 terms of BP, CC and MF are listed in Fig. 7. Of these, 3 (positive regulation of dipeptide transmembrane transport, mannitol transport and formate transport), 2 (ectoplasm and brush border membrane) and 3 (mycocerosate synthase activity, formate efflux transmembrane transporter activity and formate transmembrane transporter activity) terms were most significantly enriched in BP, CC and MF, respectively. The enriched GO terms 


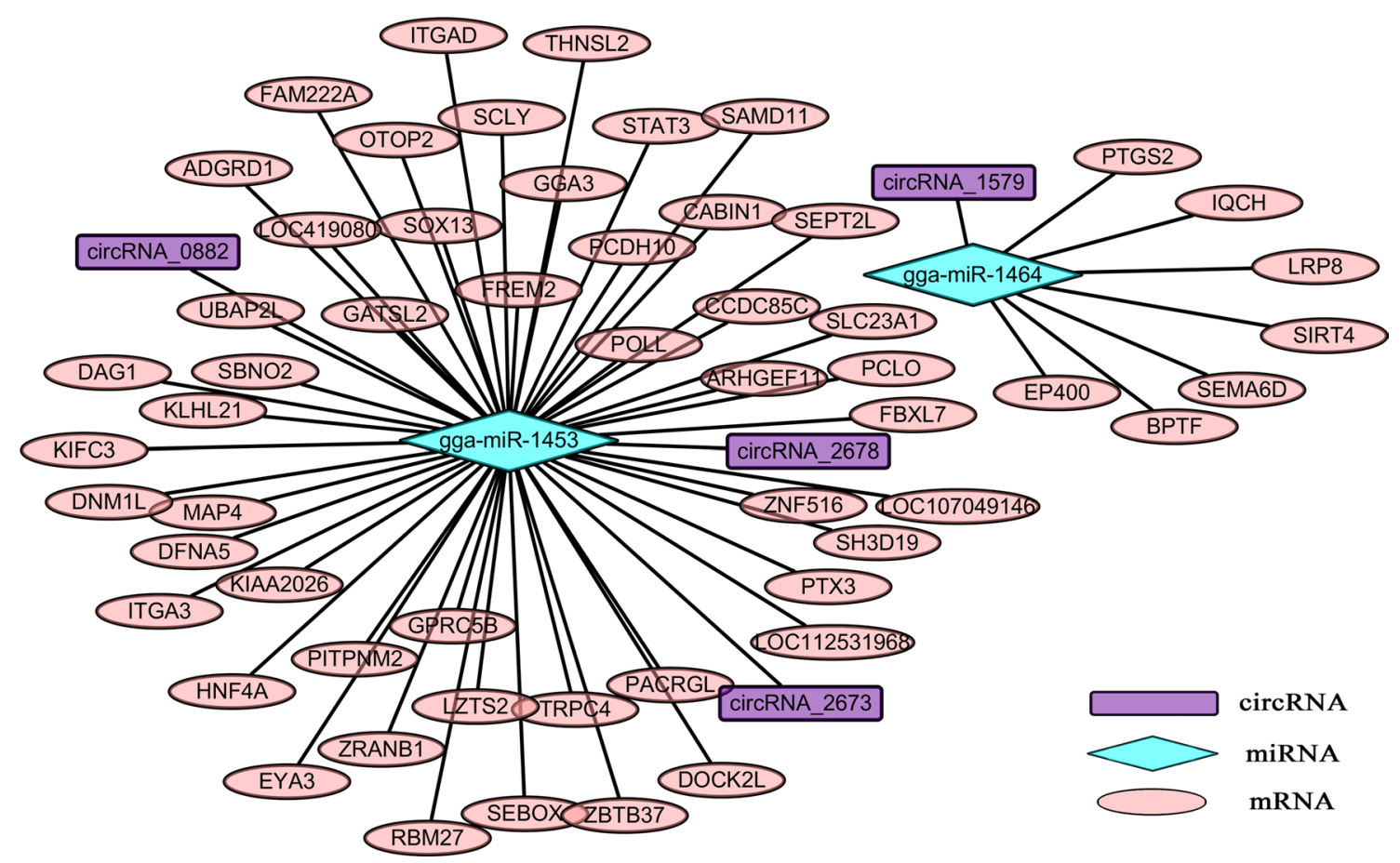

Fig. 6 circRNA-miRNA-targets network generated using Cytoscape 3.6.1. The network consists of 4 circRNAs, 2 miRNAs and 56 targets

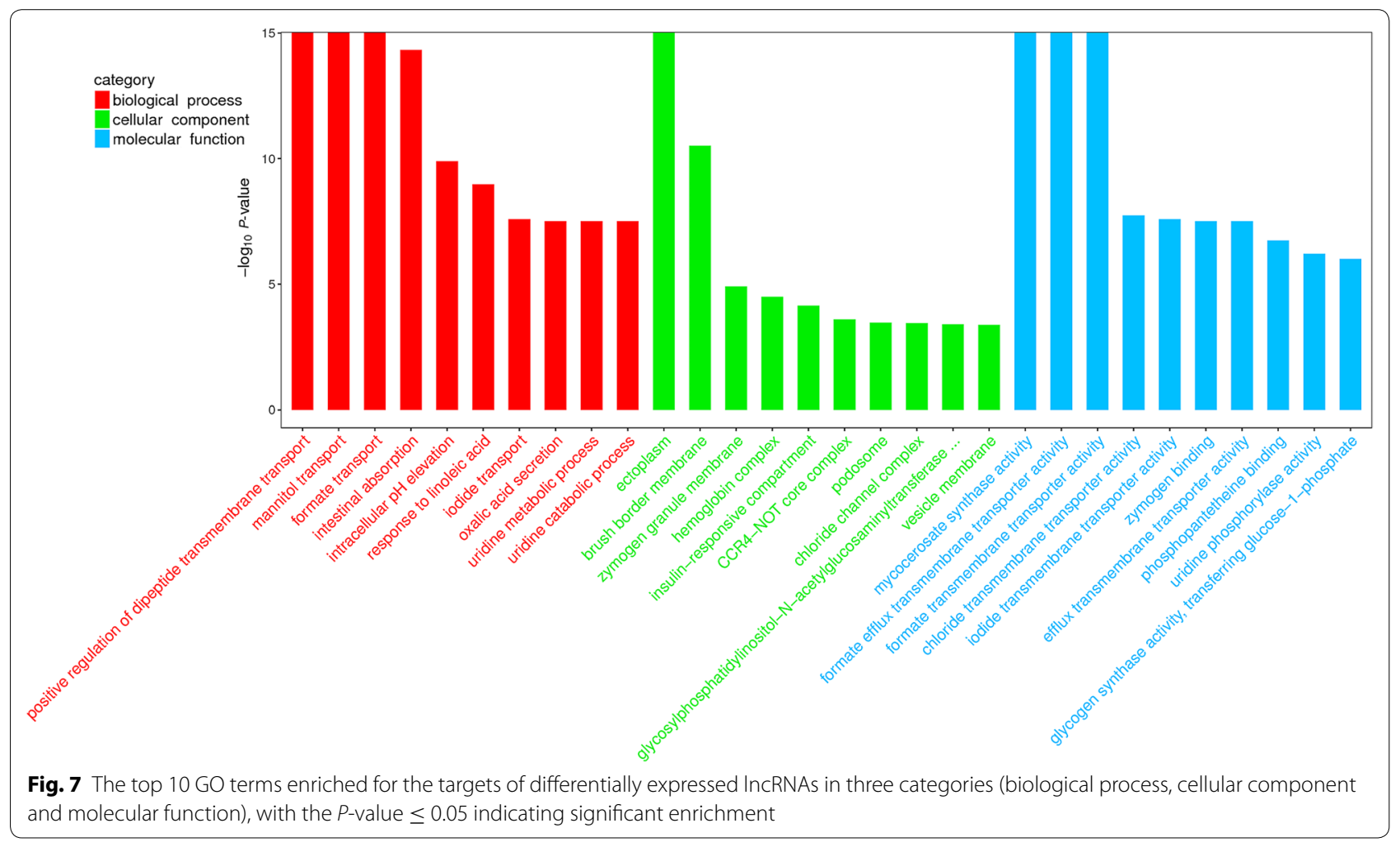




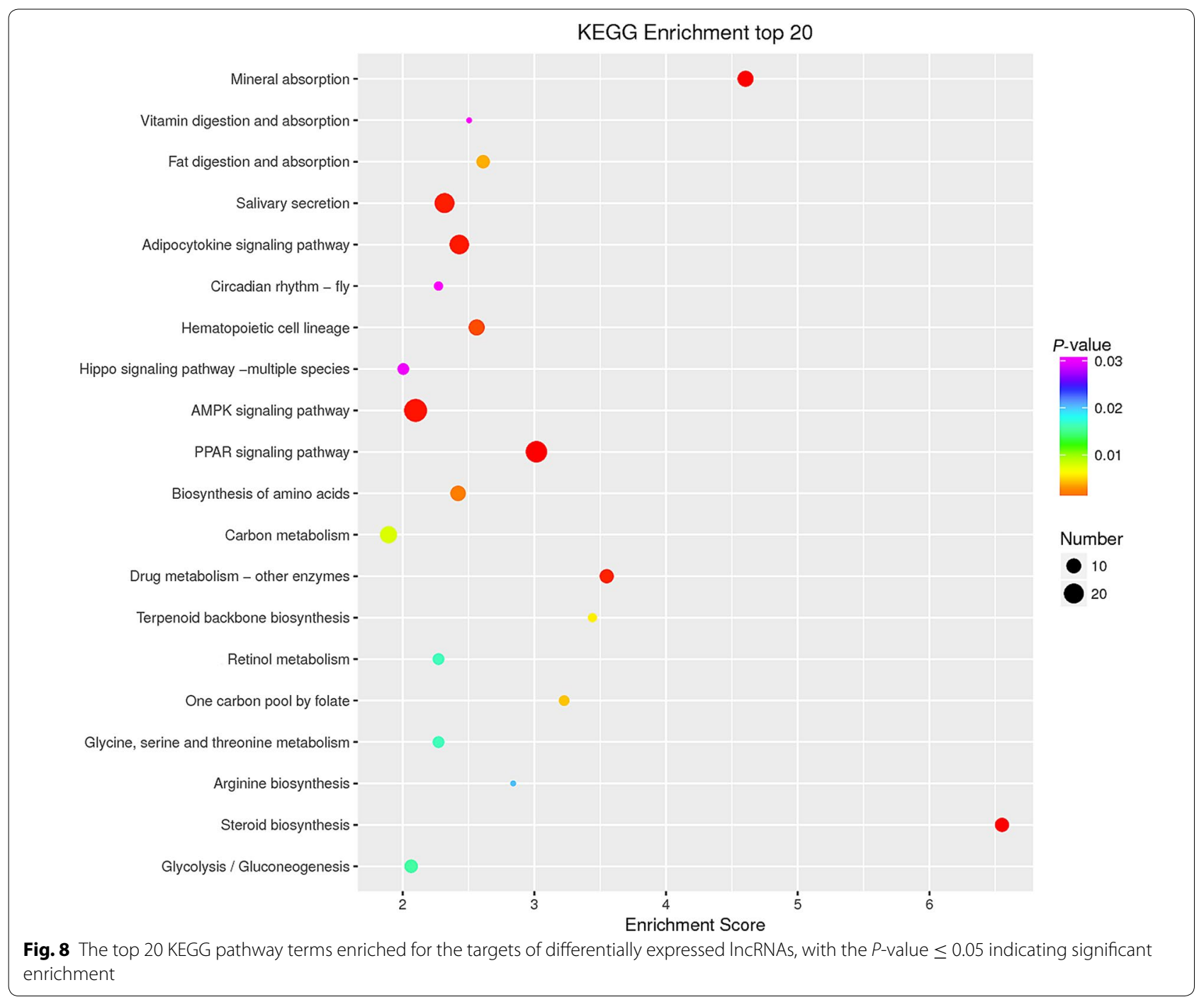

of cis-targets included apoptotic process, cell differentiation, serine-type endopeptidase inhibitor activity, and oxidoreductase activity (Additional file 8: Data S8), while the candidate trans-targets were significantly enriched in the CCR4-NOT core complex, glycosylphosphatidylinositol-N-acetylglucosaminyltransferase (GPI-GnT) complex, transferring glucose-1-phosphate, cellular response to fructose stimulus, transport of mannitol, formate and iodide, metabolism of uridine, and intestinal absorption of brush border membrane (Additional file 9: Data S9). KEGG pathway analysis showed that the potential targets of the aberrantly expressed lncRNAs were enriched in 40 pathways (Fig. 8, Additional file 7: Data S7) and the most significantly enriched pathways included immunity (PPAR signaling pathway, AMPK signaling pathway and hippo signaling pathway), intestinal absorption (e.g. mineral absorption, fat digestion and absorption and vitamin digestion and absorption), metabolism (e.g. adipocytokine signaling pathway, drug metabolism, carbon metabolism, glucose, glycine, serine and threonine metabolism and retinol metabolism), biosynthesis (e.g. steroid biosynthesis, biosynthesis of amino acids and arginine biosynthesis), and hematopoietic cell lineage. The significantly enriched 31 and 40 pathways of cis- and trans-targets are listed in Additional file 8: Data S8 and Additional file 9: Data S9, respectively.

The source and target genes of potential sponged miRNAs of 13 differentially expressed circRNAs were submitted to GO and KEGG pathway databases to predict the functions of these circRNAs. A total of $73 \mathrm{GO}$ terms and 7 KEGG pathways were significantly enriched for source genes (Additional file 10: Data S10). Of these, 3 (Golgi membrane, Golgi apparatus, extracellular exosome) and 1 (zinc ion binding) terms were most enriched in $\mathrm{CC}$ and MF, respectively, while the most enriched KEGG pathways were lysosome, cell adhesion molecules 


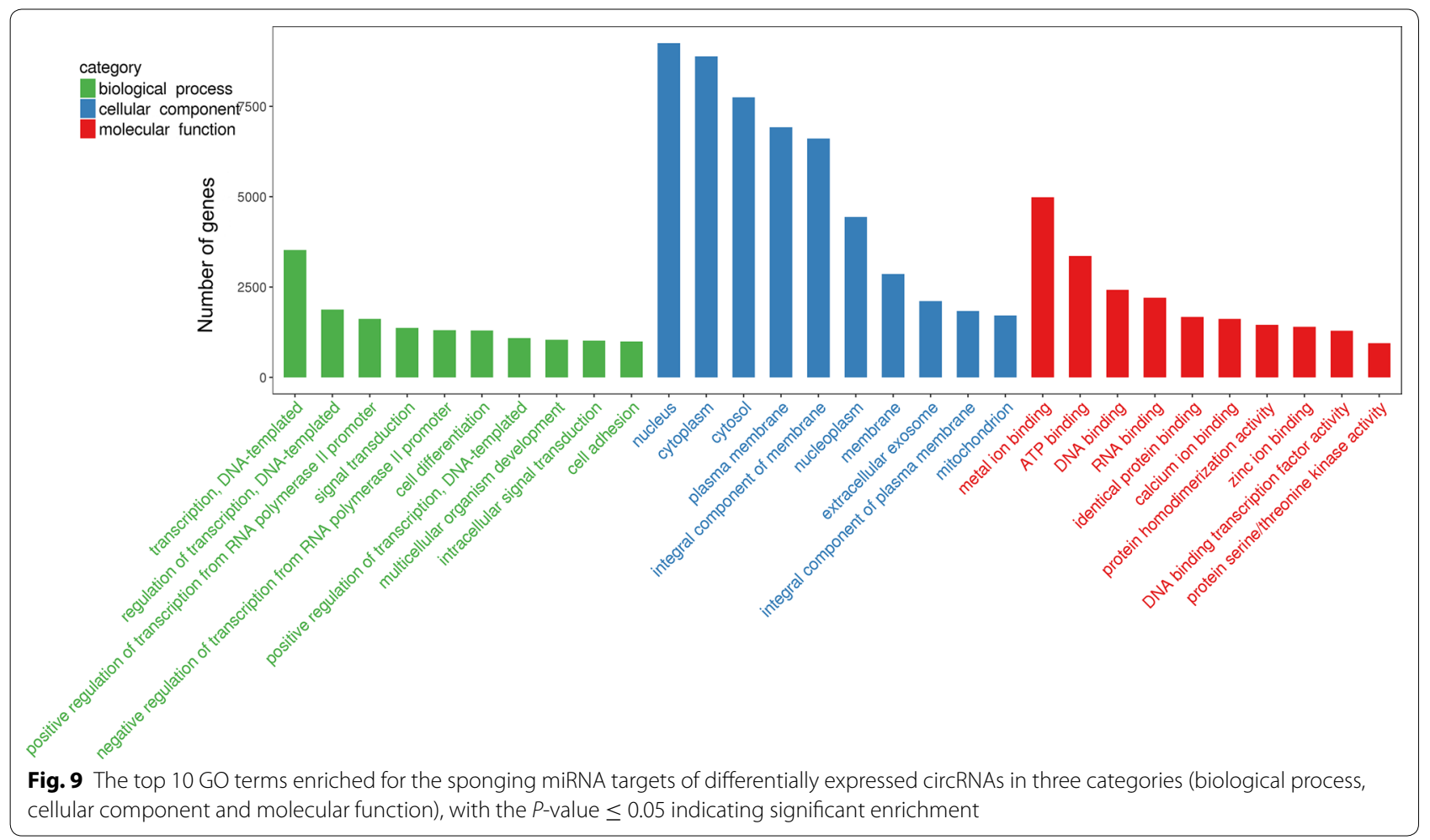

(CAMs), hippo signaling pathway, inositol phosphate metabolism, phosphatidylinositol signaling system, adherens junction and rap1 signaling pathway. With regard to the sponged miRNA targets of the aberrantly expressed circRNAs, a total of 8130 GO terms and 89 KEGG pathways were significantly enriched (Figs. 9, 10, Additional file 11: Data S11).

\section{Discussion}

In recent decades, the ncRNAs previously believed to be random transcription "noise" have been found to regulate numerous biological processes and disease development at epigenetic, transcriptional, and post-transcriptional levels [58, 59, 65]. Of these, lncRNAs were aberrantly expressed during infections of bacteria (e.g. Helicobacter pylori, Talaromyces marneffei), viruses (e.g. HIV, porcine circovirus 2, HSV-1, rabies virus, avian leukosis virus J, bovine viral diarrhea virus) and parasites (e.g. Echinococcus granulosus, Cryptosporidium parvum, Cryptosporidium baileyi) in animals and humans [28, 33, 66-73]. The expression profiles of host circRNAs were also elucidated after infections of avian leukosis virus J [74], bovine viral diarrhea virus [75], human cytomegalovirus [76], Orf virus [30], porcine endemic diarrhea virus [29], HIV [77], transmissible gastroenteritis virus [78], Mycobacterium tuberculosis [79], Clostridium perfringens [80] and $C$. baileyi [33]. Furthermore, the pivotal regulatory roles of some lncRNAs (e.g. PFB1055- $b s d$, SOX2OT and NR_045064) and circRNAs (e.g. hsa_circ_0001400) in these infections were well defined [81-84]. Coccidiosis, a deadly disease of chickens worldwide, seriously hampers birds' productivity and welfare [85]. However, most previous studies mainly focused on revealing the functions of protein molecules or protein-coding genes during Eimeria infection [86-89]. In the present study, we first identified 818 lncRNAs and 4153 circRNAs in mid-segments of chicken small intestines at $108 \mathrm{~h}$ pi of $E$. necatrix, and found that 95 lncRNAs and 13 circRNAs were significantly differentially regulated due to infection. Functional analysis of these differentially expressed ncRNAs indicated that they might play significant regulatory roles in infection of $E$. necatrix.

Accumulating evidence indicates poor conservation in the nucleotide sequences of lncRNA transcripts across humans and different animal species and tissue-specificity within a single species $[90,91]$. Although much efforts were made to unveil the mystery of lncRNAs in animals and humans in the last decades $[58,59,65]$, the available data of lncRNAs in chicken tissues at physiological or disease conditions are limited. Using the RNA-seq technology, previous studies have identified 4404, 2481, 39,907, 8691, 1376, 6543, 2597 and 2056 lncRNAs in breast muscle, spleen, cerebrum, ovarian follicle, trachea, liver, testis and adipose of chickens, respectively [33, 92-98]. 


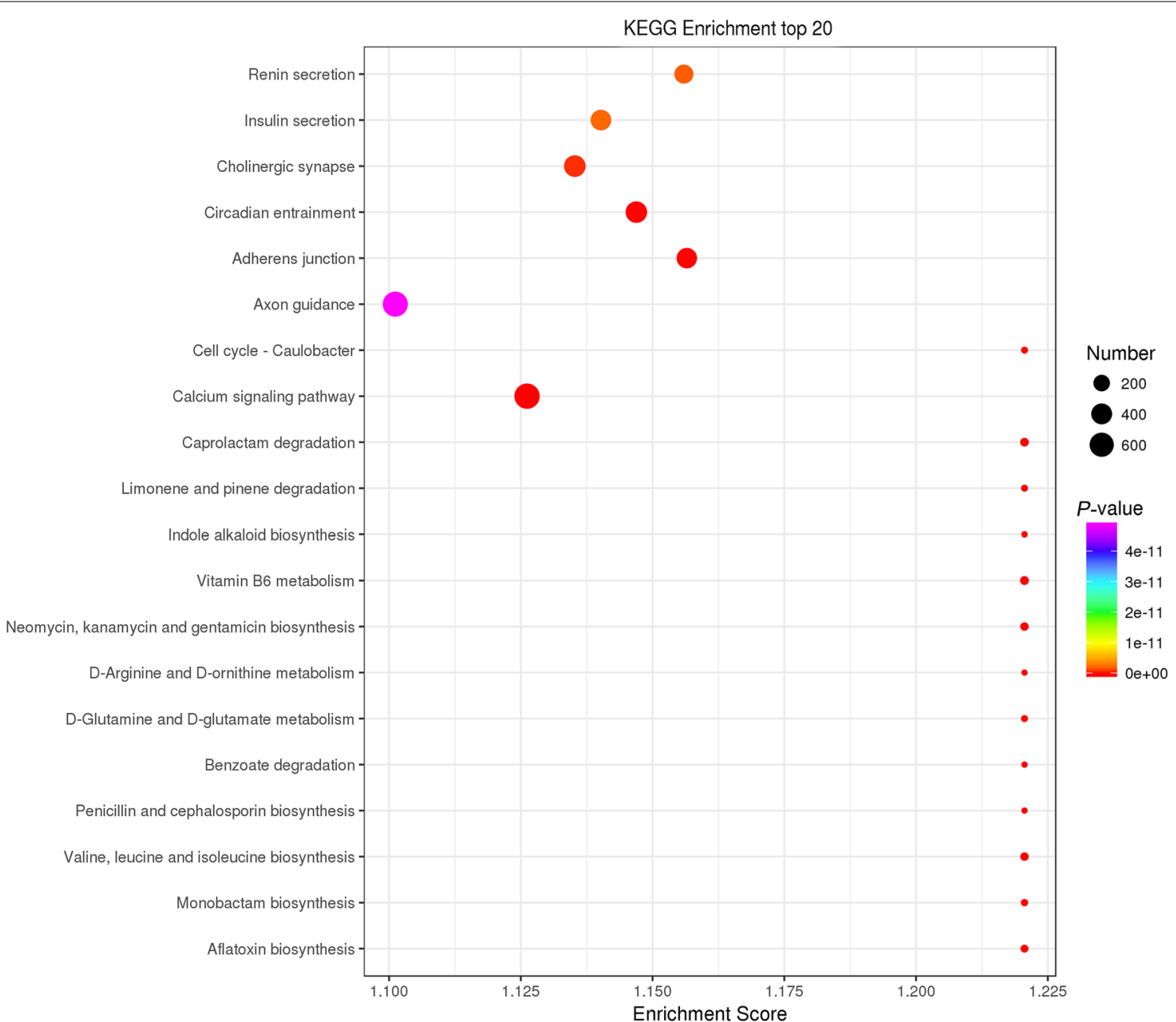

Fig. 10 The top 20 KEGG pathway terms enriched for the sponging miRNA targets of differentially expressed circRNAs, with the $P$-value $\leq 0.05$ indicating significant enrichment

Moreover, Kern et al. [99] found 9393 lncRNAs in eight tissue types (adipose, cerebellum, cortex, hypothalamus, liver, lung, skeletal muscle and spleen) of chickens and Hong et al. [100] obtained 6900 lncRNAs genes in 20 different tissues (breast, gizzard, liver, pancreas, uterus, heart, bone marrow, kidney, cerebrum, cerebellum, eye, immature egg, mature egg, gall-bladder, comb, shank, skin, lung, spleen and fascia) of an individual Ogye, with $c .75 \%$ of lncRNAs as tissue-specific. In the present study, 818 candidate IncRNAs were identified in the mid-segments of chicken small intestines. Of these, 571 lncRNAs, unmatched in the NCBI database and lncRNA database (http://www.noncode.org/download.php), may be considered novel, thus expanding the IncRNA database for chickens.

Previous studies have shown that lncRNAs acted as crucial regulators in the onset and progression of various infectious diseases through cis- and trans-manners
$[101,102]$. In the present study, E. necatrix infection significantly altered the expression profiles of $818 \mathrm{lncR}$ NAs, including 247 known and 571 putative lncRNAs. However, surprisingly, all these aberrantly expressed lncRNAs were not well characterized. To better understand the potential regulatory roles of these differentially regulated lncRNAs, their cis- and trans-targets were predicted by constructing the co-expression networks of differentially expressed lncRNAs and mRNAs. A total of 73 mRNAs were potentially cis-regulated by 38 lncRNAs. Among them, the upregulated protein kinase $C$ delta (PRKCD) would be regulated by the putative upregulated lncRNA NONGGAT002061.2. In the human ewing sarcoma cell line, PRKCD could activate $\mathrm{mTOR}$ through phosphorylation and inactivation of TSC2 [103], while the TOR pathway has been identified to be a regulator of the cell apoptosis and autophagy in chicken small intestines induced by arsenic [104] 
and a key player linking specific extracellular milieu and intracellular metabolism during Salmonella infection in chicken [105]. The downregulated ring finger protein 152 (RNF152) predicted to be regulated by the putative downregulated lncRNA NONGGAT004163.2 was localized in lysosomes and could prompt apoptosis of Hela cells [106]. In addition, 1453 mRNAs were also predicted to be trans-regulated by 87 incRNAs. For example, the upregulated type I interferon receptor subunit 1 (IFNAR1) gene was regulated by 2 upregulated (TCONS_00018115 and NONGGAT001393.2) and 2 downregulated (NONGGAT002425.2 and NONGGAT011837.2) lncRNAs. Previous studies indicated that the IFNAR abundance could indirectly enhance the host defense against foreign pathogens and limit cell proliferation of hepatocellular carcinoma [107, 108]. During infection with the infectious bursal disease virus (IBDV), IFNAR1 was also upregulated in DF1 cells and the IBDV replication could be prompted through the negative regulation of CK1 $\alpha$ on the abundance of IFNAR1 [108]. The downregulated PIK3R1 gene would be also regulated by TCONS_00018115. This gene was also downregulated during Mycoplasma gallisepticum (MG) infection, and it could be targeted by gga-miR-16-5p to inhibit cell proliferation and promote cell apoptosis through affecting the PI3K/Akt/NF-KB pathway, thereby exerting the antiinflammatory effect [109]. The downregulated SAM and SH3 domain-containing protein 1 (SASH1) would be trans-regulated by 24 lncRNAs (including 12 upregulated and 12 downregulated) and was associated with positive regulation of the p38 MAPK cascade. MAPK has been proved to be an important pathway in the pathogenesis of apicomplexan parasites $[110,111]$, and the inhibition of the p38 MAPK pathway could reduce parasite motility and micronemal protein secretion and impair cell invasion of E. tenella [112]. Furthermore, the CD36 gene, one of significantly downregulated mRNAs in the present study, was co-expressed with 71 lncRNAs (Additional file 4: Data S4), and this gene was also downregulated during co-infections of E. acervulina, E. maxima and $E$. brunetti [113]. CD36 has been identified to be a known fatty acid transport protein to facilitate uptake of circulating non-esterified fatty acids from circulation into myocytes $[114,115]$. Further analysis indicated that the CD36 could recruit the TLR4/6 receptor and induce the TLR4/6 phosphorylation after binding its ligand oxidized LDL (ox-LDL) to activate the inflammatory reaction through the NF-kB pathway $[116,117]$. These findings suggest that these differentially regulated lncRNAs may have a role in immune defense against $E$. necatrix infection. On the other hand, in the present study, one upregualted mRNA (SOCS3), potentially trans-regulated by 32 lncRNAs (Additional file 5: Data S5), was also found to be upregulated during infection with Duck hepatitis A virus type 1 (DHAV-1). Overexpression of SOCS3 significantly inhibited the expression of IFN $\alpha$, and indirectly decreased the expression of the antiviral proteins MX1 and OASL through inhibiting Janus kinase (JAK)-STAT signaling pathway, thus ultimately promoting viral proliferation and assisting in viral adaptation of DHAV-1 in chicken embryos [118]. However, SOCS3 overexpression could promote the expression of IFN- $\gamma$, and the IFN- $\gamma$ has been found to play a critical role in host defense against $E$. tenella infection $[119,120]$. Therefore, the unequivocal role of this mRNA and its regulated lncRNAs should be further determined in further studies.

To systematically and integrally understand the potential functions of lncRNAs in E. necatrix infection, we performed the GO and KEGG pathway enrichment analysis with 1543 possible target mRNAs of $95 \mathrm{lncR}$ NAs. Interestingly, GO BP analysis showed that the differentially regulated mRNAs were significantly enriched in intestinal absorption, intracellular $\mathrm{pH}$ elevation, positive regulation of dipeptide transmembrane transport, uridine metabolic and catabolic processes, and transport of iodide, mannitol and formate. GO CC analysis revealed that these genes were clustered into ectoplasm, brush border membrane, hemoglobin complex, insulinresponsive compartment, chloride channel complex and GPI-GnT complex. GO MF analysis indicated that these targets were grouped into efflux transmembrane transporter activity, uridine phosphorylase activity, glycogen synthase activity, transferring glucose-1-phosphate, and transmembrane transporter of formate, chloride and iodide. These categories have been proven to be closely associated with pathogenic mechanisms of intestinal pathogens, including Eimeria spp. [4, 24, 121]. The KEGG pathway analysis demonstrated that these differentially expressed lncRNAs would be involved in immune-related biological processes (e.g. PPAR signaling pathway, AMPK signaling pathway and hippo signaling pathway), nutritional absorption (e.g. mineral, vitamin and fat), biosynthesis (e.g. steroid, terpenoid backbone and arginine) and metabolism (e.g. glucose, carbon, retinol, glycine, serine and threonine) processes, suggesting the implicated functions of these lncRNAs in the complex interplay between chicken and E. necatrix. Additionally, enzymes of drug metabolism were enriched by KEGG pathway analysis of both cis- and trans-targets, implicating that these genes are associated with sensitivity or resistance of drugs combating E. necatrix. However, these intriguing findings should be further confirmed in future research.

Of a variety of known biological potential functions (e.g. miRNA target decoys, RNA binding protein sponges and transcriptional regulators) of circRNAs [122, 123], emerging data evidenced that sponging miRNAs are now 
one well-recognized regulatory mechanism of circRNAs [60], although miRNA inhibition as a general feature of circRNAs is currently debated [122, 124, 125]. However, in our study, regrettably, the expression profiles of miRNAs during $E$. necatrix infection were not determined. Alternatively, the potential target miRNAs of the significantly aberrantly expressed circRNAs were just predicted based on sequence complementarity by using bioinformatics analysis, and the potential functions of these circRNAs were annotated by using GO and KEGG enrichment analysis of sponging miRNA target genes. A total of 13 significantly differentially regulated circRNAs would indirectly regulate 40,464 chicken mRNAs through sponging 109 miRNAs. GO analysis showed that these mRNAs were significantly enriched in signal transduction, regulation of DNA transcription and transcription from RNA polymerase II promoter, cell adhesion, multicellular organism development, DNA binding transcription factor activity, protein serine/threonine kinase activity, and binding of ATP, DNA, RNA, metal and calcium ions. KEGG analysis indicated that these genes would be involved in pathways of biosynthesis (e.g. valine, leucine, isoleucine, neomycin, kanamycin, gentamicin, aflatoxin and indole alkaloid), metabolism (e.g. vitamin $\mathrm{B} 6, \mathrm{D}$-arginine and $\mathrm{D}$-ornithine), and neurohormonal regulation (e.g. cholinergic synapse, renin secretion, insulin secretion and axon guidance). Additionally, a previous study implicated that the circRNA could compete the RNA-binding protein to affect the translation of its cognate gene [126]. Therefore, the present study also performed the functional analysis of the source genes of 13 significantly aberrantly expressed circRNAs. Of these, only 8 (5 upregulated and 3 downregulated) and 3 upregulated genes were significantly enriched in $73 \mathrm{GO}$ and 7 KEGG terms, respectively (Additional file 10: Data S10). These findings suggest that circRNAs would participate in these pathways to regulate $E$. necatrix infection.

Notably, some limitations also exist in the present study. First, the time point for studying was limited and the dynamics of RNA expression profiles was not determined. Also, the single time point for each chicken would affect the specificity of RNA transcripts related to E. necatrix infection. Secondly, chicken tissues or organs other than the infection site (mid-segment of the small intestine) were not included, such as spleen and blood, in which the host immune response would be apparently reflected. Thirdly, the miRNA profiles were not examined in the present study. Since both lncRNAs and circRNAs were proved to be ceRNAs acting with miRNAs, RNA sequencing of miRNA expression would be valuable for further studying the potential regulatory roles of differentially regulated lncRNAs and circRNAs during E. necatrix infection.
Last but not least, there was not enough evidence about the biological replication with only a single E. necatrix isolate. Although samples from three chickens for both the $\mathrm{N}$ and $\mathrm{S}$ groups were analyzed, and the purity and the oocyst sporulation rate were improved in our study, this cannot absolutely ensure that the specific RNA transcripts relate to E. necatrix infection. Therefore, it is of significant importance that future research investigates these limitations.

\section{Conclusions}

The present study conducted comprehensive genomic analysis of the effect of $E$. necatrix infection on the expression patterns of chicken mRNAs, lncRNAs and circRNAs. The expression of 1543 mRNAs, 95 lncRNAs and 13 circRNAs was significantly altered at 108 $\mathrm{h}$ pi, and functional prediction using GO and KEGG pathway analysis implicated significant roles of these genes during E. necatrix infection. To the best of our knowledge, this is the first report to profile these genes in chickens during E. necatrix infection, and is also the first investigation on expression profiles of lncRNAs and circRNAs in coccidium infection. Therefore, the findings in the present study shed a new insight into understanding the underlying mechanisms of the interaction of Eimeria spp. and chicken intestinal cells.

\section{Supplementary information}

Supplementary information accompanies this paper at https://doi. org/10.1186/s13071-020-04047-9.

Additional file 1: Data S1. The primers used for verification of differentially expressed mRNAs, IncRNAs and circRNAs by qRT-PCR.

Additional file 2: Data S2. All the expressed mRNAs, IncRNAs and circRNAs in this study.

Additional file 3: Data S3. The length distribution of IncRNAs and circRNAs.

Additional file 4: Data S4. The target genes predicted for differentially expressed IncRNAs.

Additional file 5: Data S5. The cis- and trans-target genes predicted for differentially expressed IncRNAs.

Additional file 6: Data S6. The sponging miRNAs predicted for differentially expressed circRNAs and their potential targets.

Additional file 7: Data S7. The GO and KEGG pathway enrichment analysis of target genes for the differentially expressed IncRNAs.

Additional file 8: Data S8. The GO and KEGG pathway enrichment analysis of cis-target genes for the differentially expressed IncRNAs.

Additional file 9: Data S9. The GO and KEGG pathway enrichment analysis of trans-targets for the differentially expressed IncRNAs.

Additional file 10: Data S10. The GO and KEGG pathway enrichment analysis of source genes for the differentially expressed circRNAs.

Additional file 11: Data S11. The GO and KEGG pathway enrichment analysis of sponging miRNA targets for the differentially expressed circRNAs. 


\section{Abbreviations}

AMPK: adenosine 5'-monophosphate (AMP)-activated protein kinase; BP: biological process; N: control group; CAMs: cell adhesion molecules; CC: cellular component; CCR4: CC chemokine receptor-4; cDNA: complementary DNA; ceRNA: competing endogenous RNA; circRNAs: circular RNAs; CK1a: casein kinase 1 alpha; CNCl: coding-non-coding index; CPC: coding potential calculator; DF1: Douglas Foster-1; DHAV-1: Duck hepatitis A virus type 1; ECM: extracellular matrix; FC: fold change; FPKM: fragments per kb per million reads; GAPDH: glyceraldehyde-3-phosphate dehydrogenase; GO: Gene Ontology; GPI-GnT: glycosylphosphatidylinositol-N-acetylglucosaminyltransferase; $h$ : hour; HIV: human immunodeficiency virus; HSV-1: herpes simplex virus-1; IBDV: infectious bursal disease virus; IFNAR1: interferon receptor subunit 1;

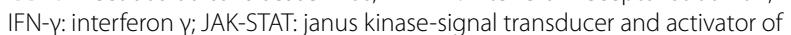
transcription; KEGG: Kyoto Encyclopedia of Genes and Genomes; IncRNAs: long-non-coding RNAs; MAPK: mitogen-activated protein kinase; MF: molecular function; MG: Mycoplasma gallisepticum; mTOR: mammalian target of rapamycin; NB: negative binomial; NCBI: National Center for Biotechnology Information; ncRNAs: non-coding RNAs; ox-LDL: oxidized LDL; PBS: phosphate-buffered saline; PCC: paired chiastic clipping; PH: pondus hydrogenii; pi: post-infection; PIK3R1: phosphoinositide-3-kinase regulatory subunit 1; PLEK: predictor of long non-coding RNAs and messenger RNAs based on an improved k-mer scheme; PPAR: peroxisome proliferators-activated receptors; PRKCD: protein kinase C delta; Q30: Qphred > 30; qRT-PCR: quantitative real-time polymerase chain reaction; RIN: RNA integrity number; RNA-seq: RNA sequencing; RNF152: ring finger protein 152; RPM: reads per million; S: experimental group; SAM: sequence alignment/map; SASH1: SAM and SH3 domain containing 1; SOCS3: suppressor of cytokine signaling 3; SOX2OT: (sex determining region Y)-box 2 overlapping transcript; SRA: sequence read archive; TLR: toll-like receptors; TSC2: tuberous sclerosis 2.

\section{Acknowledgements}

Not applicable.

\section{Authors' contributions}

GHZ conceived and designed the experiments. XCF and TLL performed the experiments and drafted manuscript. XCF, TLL, YW, XMW, YXW, PL and JKS analyzed the data. XCF and TLL contributed to reagents and materials. All authors read and approved the final manuscript.

\section{Funding}

This study was funded by a grant from the National Key Research and Development Program of China (Grant number 2017YFD0501200).

\section{Availability of data and materials}

The raw data of sequencing reads are submitted to the NCBI SRA database under the accession numbers SRR9331386 and SRR9331387.

\section{Ethics approval and consent to participate}

This study was carried out strictly in accordance with the recommendations in the Guide for the Care and Use of Laboratory Animals of the Ministry of Health, China. Our protocol with all animal experiments was approved by the Research Ethics Committee of Northwest A\&F University, Yangling, China. All efforts were made to minimize the pain of animals used in this study.

\section{Consent for publication}

Not applicable.

\section{Competing interests}

The authors declare that they have no competing interests.

\section{Author details}

${ }^{1}$ Department of Parasitology, College of Veterinary Medicine, Northwest A\&F University, Yangling 712100, China. ${ }^{2}$ Center of Animal Disease Prevention and Control of Huyi District, Xi'an 710300, China. ${ }^{3}$ State Key Laboratory of Veterinary Etiological Biology, Key Laboratory of Veterinary Parasitology of Gansu Province, Lanzhou Veterinary Research Institute, Chinese Academy of Agricultural Sciences, Lanzhou 730000, China.

Received: 3 January 2020 Accepted: 27 March 2020

Published online: 03 April 2020

\section{References}

1. Williams RB. A compartmentalised model for the estimation of the cost of coccidiosis to the world's chicken production industry. Int J Parasitol. 1999;29:1209-29.

2. Dalloul RA, Lillehoj HS. Recent advances in immunomodulation and vaccination strategies against coccidiosis. Avian Dis. 2005;49:1-8.

3. Allen PC. Nitric oxide production during Eimeria tenella infections in chickens. Poult Sci. 1997;76:810-3.

4. Guo A, Cai J, Gong W, Yan H, Luo X, Tian G, et al. Transcriptome analysis in chicken cecal epithelia upon infection by Eimeria tenella iin vivo. PLoS ONE. 2013;8:e64236.

5. Shirley MW, Ivens A, Gruber A, Madeira AM, Wan KL, Dear PH, et al. The Eimeria genome projects: a sequence of events. Trends Parasitol. 2004;20:199-201.

6. Hao L, Liu X, Zhou X, Li J, Suo X. Transient transfection of Eimeria tenella using yellow or red fluorescent protein as a marker. Mol Biochem Parasitol. 2007;153:213-5.

7. Blake DP, Tomley FM. Securing poultry production from the ever-present Eimeria challenge. Trends Parasitol. 2014;30:12-9.

8. Williams RB. Anticoccidial vaccines for broiler chickens: pathways to success. Avian Pathol. 2002;31:317-53.

9. Kim CH, Lillehoj HS, Bliss TW, Keeler CL Jr, Hong YH, Park DW, et al. Construction and application of an avian intestinal intraepithelial lymphocyte cDNA microarray (AVIELA) for gene expression profiling during Eimeria maxima infection. Vet Immunol Immunopathol. 2008;124:341-54.

10. Peek HW, Landman WJ. Coccidiosis in poultry: anticoccidial products, vaccines and other prevention strategies. Vet Q. 2011;31:143-61.

11. Godwin RM, Morgan JA. A molecular survey of Eimeria in chickens across Australia. Vet Parasitol. 2015;214:6-21.

12. Innes EA, Vermeulen AN. Vaccination as a control strategy against the coccidial parasites Eimeria, Toxoplasma and Neospora. Parasitology. 2006;133:S145-68.

13. Blake DP, Shirley MW, Smith AL. Genetic identification of antigens protective against coccidia. Parasite Immunol. 2006:28:305-14.

14. Lee BH, Kim WH, Jeong J, Yoo J, Kwon YK, Jung BY, et al. Prevalence and cross-immunity of Eimeria species on Korean chicken farms. J Vet Med Sci. 2010;72:985-9.

15. Shah MA, Xu L, Yan R, Song X, Li X. Cross immunity of DNA vaccine pVAX1-cSZ2-IL-2 to Eimeria tenella, E. necatrix and E. maxima. Exp Parasitol. 2010;124:330-3.

16. Knoll $L J$, Furie GL, Boothroyd JC. Adaptation of signature-tagged mutagenesis for Toxoplasma gondii: a negative screening strategy to isolate genes that are essential in restrictive growth conditions. Mol Biochem Parasitol. 2001;116:11-6.

17. Kim DK, Hong YH, Park DW, Lamont SJ, Lillehoj HS. Differential immunerelated gene expression in two genetically disparate chicken lines during infection by Eimeria maxima. Dev Biol. 2008;132:131-40.

18. Katrib M, Ikin RJ, Brossier F, Robinson M, Slapetova I, Sharman PA, et al. Stage-specific expression of protease genes in the apicomplexan parasite, Eimeria tenella. BMC Genomics. 2012;13:685.

19. Kinga Modrzynska K, Creasey A, Loewe L, Cezard T, Trindade Borges S, Martinelli A, et al. Quantitative genome re-sequencing defines multiple mutations conferring chloroquine resistance in rodent malaria. BMC Genomics. 2012;13:106.

20. Blake DP. Eimeria genomics: Where are we now and where are we going? Vet Parasitol. 2015;212:68-74.

21. Kim DK, Lillehoj H, Min W, Kim CH, Park MS, Hong YH, et al. Comparative microarray analysis of intestinal lymphocytes following Eimeria acervulina, E. maxima, or E. tenella infection in the chicken. PLoS ONE. 2011;6:e27712.

22. Min W, Lillehoj HS, Kim S, Zhu JJ, Beard H, Alkharouf N, et al. Profiling local gene expression changes associated with Eimeria maxima and Eimeria acervulina using cDNA microarray. Appl Microbiol Biotechnol. 2003;62:392-9.

23. Kim CH, Lillehoj HS, Hong YH, Keeler CL Jr, Lillehoj EP. Comparison of global transcriptional responses to primary and secondary Eimeria acervulina infections in chickens. Dev Comp Immunol. 2010;34:344-51. 
24. Kim CH, Lillehoj HS, Hong YH, Keeler CL Jr, Lillehoj EP. Analysis of global transcriptional responses of chicken following primary and secondary Eimeria acervulina infections. BMC Proc. 2011;5:S12.

25. Balloy V, Koshy R, Perra L, Corvol H, Chignard M, Guillot L, et al. Bronchial epithelial cells from cystic fibrosis patients express a specific long non-coding RNA signature upon Pseudomonas aeruginosa infection. Front Cell Infect Microbiol. 2017;7:218.

26. Riege K, Hölzer M, Klassert TE, Barth E, Bräuer J, Collatz M, et al. Massive effect on IncRNAs in human monocytes during fungal and bacterial infections and in response to vitamins A and D. Sci Rep. 2017;7:40598.

27. Carnero E, Fortes P. HCV infection, IFN response and the coding and non-coding host cell genome. Virus Res. 2016;212:85-102.

28. Hu X, Chen S, Jia C, Xue S, Dou C, Dai Z, et al. Gene expression profile and long non-coding RNA analysis, using RNA-Seq, in chicken embryonic fibroblast cells infected by avian leukosis virus. J. Arch Virol. 2018;163:639-47.

29. Chen J, Wang H, Jin L, Wang L, Huang X, Chen W, et al. Profile analysis of circRNAs induced by porcine endemic diarrhea virus infection in porcine intestinal epithelial cells. Virology. 2019;527:169-79.

30. Pang F, Zhang M, Yang X, Li G, Zhu S, Nie X, et al. Genome-wide analysis of circular RNAs in goat skin fibroblast cells in response to Orf virus infection. PeerJ. 2019;7:e6267.

31. Zhou R, Feng Y, Chen XM. Non-coding RNAs in epithelial immunity to Cryptosporidium infection. Parasitology. 2014;141:1233-43.

32. Bayer-Santos E, Marini MM, da Silveira JF. Non-coding RNAs in hostpathogen interactions: subversion of mammalian cell functions by protozoan parasites. Front Microbiol. 2017;8:474.

33. Ren GJ, Fan XC, Liu TL, Wang SS, Zhao GH. Genome-wide analysis of differentially expressed profiles of mRNAs, IncRNAs and circRNAs during Cryptosporidium baileyi infection. BMC Genomics. 2018;19:356.

34. Morgan JA, Morris GM, Wlodek BM, Byrnes R, Jenner M, Constantinoiu $\mathrm{CC}$, et al. Real-time polymerase chain reaction (PCR) assays for the specific detection and quantification of seven Eimeria species that cause coccidiosis in chickens. Mol Cell Probes. 2009;23:83-9.

35. Kumar S, Garg R, Banerjee PS, Ram H, Kundu K, Kumar S, et al. Genetic diversity within ITS-1 region of Eimeria species infecting chickens of north India. Infect Genet Evol. 2015;36:262-7.

36. Chen RA, Wang WL, Lin RQ, Liu LD, Liao GC, Tang JH, et al. Observation of the excretion pattern of a precocious line of Eimeria necatrix and the strengthening of immune homogeneity. Exp Parasitol. 2016;164:79-83.

37. McDougald LR, Fuller AL, McMurray BL. An outbreak of Eimeria necatrix coccidiosis in breeder pullets: analysis of immediate and possible longterm effects on performance. Avian Dis. 1990;34:485-7.

38. Mattiello R, Boviez JD, McDougald LR. Eimeria brunetti and Eimeria necatrix in chickens of Argentina and confirmation of seven species of Eimeria. Avian Dis. 2000;44:711-4.

39. Shirley MW, Bellatti MA, Millard BJ. An egg-adapted (attenuated) line of Eimeria necatrix: further studies on its reproduction, pathogenicity and immunogenicity. Parasitology. 1982;84:215-26.

40. Remmler O, Mcgregor JK. A method to facilitate isolation of single coccidial oocysts. J Parasitol. 1964;50:294.

41. El-Sherry S, Ogedengbe ME, Hafeez MA, Barta JR. Divergent nuclear 185 rDNA paralogs in a turkey coccidium, Eimeria meleagrimitis, complicate molecular systematics and identification. Int J Parasitol. 2013:43:679-85.

42. Holdsworth PA, Conway DP, McKenzie ME, Dayton AD, Chapman HD, Mathis GF, et al. World Association for the Advancement of Veterinary Parasitology (WAAVP) guidelines for evaluating the efficacy of anticoccidial drugs in chickens and turkeys. Vet Parasitol. 2004;121:189-212.

43. Shi YH, He XW, Liu FD, Liu YS, Hu Y, Shu L, et al. Comprehensive analysis of differentially expressed profiles of long non-coding RNAs and messenger RNAs in kaolin-induced hydrocephalus. Gene. 2019;697:184-93.

44. Snezhkina AV, Lukyanova EN, Zaretsky AR, Kalinin DV, Pokrovsky AV, Golovyuk AL, et al. Novel potential causative genes in carotid paragangliomas. BMC Med Genet. 2019;20:48.

45. Bolger AM, Lohse M, Usadel B. Trimmomatic: a flexible trimmer for Illumina sequence data. Bioinformatics. 2014;30:2114-20.

46. Li A, Zhang J, Zhou Z. PLEK: a tool for predicting long non-coding RNAs and messenger RNAs based on an improved k-mer scheme. BMC Bioinform. 2014;15:311.
47. Gao Y, Wang J, Zhao F. CIRl: an efficient and unbiased algorithm for de novo circular RNA identification. Genome Biol. 2015;16:4.

48. Roberts A, Trapnell C, Donaghey J, Rinn JL, Pachter L. Improving RNASeq expression estimates by correcting for fragment bias. Genome Biol. 2011;12:R22.

49. Glažar P, Papavasileiou P, Rajewsky N. circBase: a database for circular RNAs. RNA. 2014;20:1666-70.

50. Arnaiz E, Sole C, Manterola L, I parraguirre L, Otaegui D, Lawrie CH. CircRNAs and cancer: biomarkers and master regulators. Semin Cancer Biol. 2018:58:90-9.

51. Cortés-López M, Gruner MR, Cooper DA, Gruner HN, Voda Al, van der Linden AM, et al. Global accumulation of circRNAs during aging in Caenorhabditis elegans. BMC Genomics. 2018;19:8.

52. Braicu C, Zimta AA, Gulei D, Olariu A, Berindan-Neagoe I. Comprehensive analysis of circular RNAs in pathological states: biogenesis, cellular regulation, and therapeutic relevance. Cell Mol Life Sci. 2019;76:1559-77.

53. John B, Enright AJ, Aravin A, TuschI T, Sander C, Marks DS. Human microRNA targets. PLoS Biol. 2004;2:e363.

54. Likhite N, Warawdekar UM. A unique method for isolation and solubilization of proteins after extraction of RNA from tumor tissue using trizol. J Biomol Technol. 2011:22:37-44.

55. Kohls K, Schmidt D, Holdenrieder S, Müller SC, Ellinger J. Detection of cell-free IncRNA in serum of cancer patients. Urologe A. 2015;54:819-25.

56. Liu TL, Fan XC, Li YH, Yuan YJ, Yin YL, Wang XT, et al. Expression profiles of mRNA and IncRNA in HCT-8 cells infected with Cryptosporidium parvum Ild subtype. Front Microbiol. 2018;9:1409.

57. Zhao Y, Luo H, Chen X, Xiao Y, Chen R. Computational methods to predict long noncoding RNA functions based on co-expression network. Methods Mol Biol. 2014;1182:209-18.

58. Adams BD, Parsons C, Walker L, Zhang WC, Slack FJ. Targeting noncoding RNAs in disease. J Clin Investig. 2017;127:761-71.

59. Kopp F, Mendell JT. Functional classification and experimental dissection of long noncoding RNAs. Cell. 2018;172:393-407.

60. Hansen TB, Jensen TI, Clausen BH, Bramsen JB, Finsen B, Damgaard CK, et al. Natural RNA circles function as efficient microRNA sponges. Nature. 2013:495:384-8.

61. Lukiw WJ, Circular RNA. circRNA) in Alzheimer's disease (AD. Front Genet. 2013:4:307.

62. Memczak S, Jens M, Elefsinioti A, Torti F, Krueger J, Rybak A, et al. Circular RNAs are a large class of animal RNAs with regulatory potency. Nature. 2013;495:333-8.

63. Xu S, Zhou L, Ponnusamy M, Zhang L, Dong Y, Zhang Y, et al. A comprehensive review of circRNA: from purification and identification to disease marker potential. PeerJ. 2018;6:e5503.

64. Zhang HD, Jiang LH, Sun DW, Hou JC, Ji ZL. CircRNA: a novel type of biomarker for cancer. Breast Cancer. 2018;25:1-7.

65. Liu W, Ding C. Roles of IncRNAs in viral infections. Front Cell Infect Microbiol. 2017;7:205.

66. LiY, Li M, Luo H, Bai J, Zhang J, Zhong X, et al. Expression profile of IncRNA in human bronchial epithelial cells response to Talaromyces marneffei infection: a microarray analysis. Microb Pathog. 2017;104:155-60.

67. Li H, Gu Z, Yang L, Tian Y, Kang X, Liu X. Transcriptome profile analysis reveals an estrogen induced IncRNA associated with lipid metabolism and carcass traits in chickens (Gallus gallus). Cell Physiol Biochem. 2018;50:1638-58.

68. Ma Q, Li L, Tang Y, Fu Q, Liu S, Hu S, et al. Analyses of long non-coding RNAs and mRNA profiling through RNA sequencing of MDBK cells at different stages of bovine viral diarrhea virus infection. Res Vet Sci. 2017;115:508-16.

69. Cui YH, Song XL, Hu ZX, Yang G, Li ZJ, Pan HW. Transcriptional profile and integrative analyses of long noncoding RNAs in primary human corneal epithelial cells in response to HSV-1 infection. Curr Eye Res. 2018:43:1422-31.

70. Yu A, Wang Y, Yin J, Zhang J, Cao S, Cao J, et al. Microarray analysis of long non-coding RNA expression profiles in monocytic myeloidderived suppressor cells in Echinococcus granulosus-infected mice. Parasit Vectors. 2018;11:327. 
71. Zhao P, Liu S, Zhong Z, Jiang T, Weng R, Xie M, et al. Analysis of expression profiles of long noncoding RNAs and mRNAs in brains of mice infected by rabies virus by RNA sequencing. Sci Rep. 2018;8:11858.

72. Chu A, Liu J, Yuan Y, Gong Y. Comprehensive analysis of aberrantly expressed ceRNA network in gastric cancer with and without $H$. pylori infection. J Cancer. 2019;10:853-63.

73. Fang M, Yang Y, Wang N, Wang A, He Y, Wang J, et al. Genome-wide analysis of long non-coding RNA expression profile in porcine circovirus 2-infected intestinal porcine epithelial cell line by RNA sequencing. PeerJ. 2019;7:e6577.

74. Zhang Y, Wang L, Qiu L, Pan R, Bai H, Jiang Y, et al. Expression patterns of novel circular RNAs in chicken cells after avian leukosis virus subgroup J infection. Gene. 2019;701:72-81.

75. Li C, Li X, Hou X, Ni W, Zhang M, Li H, et al. Comprehensive analysis of circRNAs expression profiles in different periods of MDBK cells infected with bovine viral diarrhea virus. Res Vet Sci. 2019;125:52-60.

76. Lou YY, Wang QD, Lu YT, Tu MY, Xu X, Xia Y, et al. Differential circRNA expression profiles in latent human cytomegalovirus infection and validation using clinical samples. Physiol Genomics. 2019;51:51-8.

77. Zhang Y, Zhang H, An M, Zhao B, Ding H, Zhang Z, et al. Crosstalk in competing endogenous RNA networks reveals new circular RNAs involved in the pathogenesis of early HIV infection. J Transl Med. 2018;16:332.

78. Ma X, Zhao X, Zhang Z, Guo J, Guan L, Li J, et al. Differentially expressed non-coding RNAs induced by transmissible gastroenteritis virus potentially regulate inflammation and NF-KB pathway in porcine intestinal epithelial cell line. BMC Genomics. 2018;19:747.

79. Fu Y, Wang J, Qiao J, Yi Z. Signature of circular RNAs in peripheral blood mononuclear cells from patients with active tuberculosis. J Cell Mol Med. 2019;23:1917-25.

80. Yan Z, Jiang T, Wang P, Huang X, Yang Q, Sun W, et al. Circular RNA expression profile of spleen in a Clostridium perfringens type $\mathrm{C}$-induced piglet model of necrotizing enteritis. FEBS Open Bio. 2018:8:1722-32.

81. Amit-Avraham I, Pozner G, Eshar S, Fastman Y, Kolevzon N, Yavin E, et al. Antisense long noncoding RNAs regulate var gene activation in the malaria parasite Plasmodium falciparum. Proc Natl Acad Sci USA. 2015;112:E982-91.

82. Shafiee M, Aleyasin SA, Mowla SJ, Vasei M, Yazdanparast SA. The effect of microRNA-375 overexpression, an inhibitor of Helicobacter pyloriinduced carcinogenesis, on IncRNA SOX2OT. Jundishapur J Microbiol. 2016;9:e23464.

83. Li M, Gong AY, Zhang XT, Wang Y, Mathy NW, Martins GA, et al. Induction of a long noncoding RNA transcript, NR_045064, promotes defense gene transcription and facilitates intestinal epithelial cell responses against Cryptosporidium infection. J Immunol. 2018;201:3630-40.

84. Tagawa T, Gao S, Koparde VN, Gonzalez M, Spouge JL, Serquiña AP et al. Discovery of Kaposi's sarcoma herpesvirus-encoded circular RNAs and a human antiviral circular RNA. Proc Natl Acad Sci USA. 2018;115:12805-10.

85. Fatoba AJ, Adeleke MA. Diagnosis and control of chicken coccidiosis: a recent update. J Parasit Dis. 2018:42:483-93.

86. Chapman HD, Barta JR, Blake D, Gruber A, Jenkins M, Smith NC, et al. A selective review of advances in coccidiosis research. Adv Parasitol. 2013;83:93-171.

87. Chapman HD. Milestones in avian coccidiosis research: a review. Poult Sci. 2014;93:501-11.

88. Liu L, Huang X, Liu J, Li W, Ji Y, Tian D, et al. Identification of common immunodominant antigens of Eimeria tenella, Eimeria acervulina and Eimeria maxima by immunoproteomic analysis. Oncotarget. 2017:8:34935-45.

89. Miska KB, Fetterer RH. The mRNA expression of amino acid and sugar transporters, aminopeptidase, as well as the di- and tri-peptide transporter PepT1 in the intestines of Eimeria infected broiler chickens. Poult Sci. 2017;96:465-73.

90. Mercer TR, Dinger ME, Sunkin SM, Mehler MF, Mattick JS. Specific expression of long noncoding RNAs in the mouse brain. Proc Natl Acad Sci USA. 2008;105:716-21.
91. Haemmerle M, Gutschner T. Long non-coding RNAs in cancer and development: where do we go from here? Int J Mol Sci. 2015;16:1395-405.

92. Liu Y, Sun Y, LiY, Bai H, Xue F, Xu S, et al. Analyses of long non-coding RNA and mRNA profiling using RNA sequencing in chicken testis with extreme sperm motility. Sci Rep. 2017;7:9055.

93. Muret K, Klopp C, Wucher V, Esquerré D, Legeai F, Lecerf F, et al. Long noncoding RNA repertoire in chicken liver and adipose tissue. Genet Sel Evol. 2017:49:6.

94. Li D, Bao P, Yin Z, Sun L, Feng J, He Z, et al. Exploration of the involvement of IncRNA in HIV-associated encephalitis using bioinformatics. PeerJ. 2018;6:e5721.

95. Li D, Li F, Jiang K, Zhang M, Han R, Jiang R, et al. Integrative analysis of long noncoding RNA and mRNA reveals candidate IncRNAs responsible for meat quality at different physiological stages in Gushi chicken. PLoS ONE. 2019;14:e0215006.

96. Peng Y, Chang L, Wang Y, Wang R, Hu L, Zhao Z, et al. Genome-wide differential expression of long noncoding RNAs and mRNAs in ovarian follicles of two different chicken breeds. Genomics. 2019;111:1395-403.

97. Xu Z, Che T, Li F, Tian K, Zhu Q, Mishra SK, et al. The temporal expression patterns of brain transcriptome during chicken development and ageing. BMC Genomics. 2018;19:917.

98. You Z, Zhang Q, Liu C, Song J, Yang N, Lian L. Integrated analysis of IncRNA and mRNA repertoires in Marek's disease infected spleens identifies genes relevant to resistance. BMC Genomics. 2019;20:245.

99. Kern C, Wang Y, Chitwood J, Korf I, Delany M, Cheng H, et al. Genomewide identification of tissue-specific long non-coding RNA in three farm animal species. BMC Genomics. 2018;19:684.

100. Hong H, Chai HH, Nam K, Lim D, Lee KT, Do YJ, et al. Non-coding transcriptome maps across twenty tissues of the Korean black chicken, Yeonsan Ogye. Int J Mol Sci. 2018;19:E2359.

101. Yan P, Luo S, Lu JY, Shen X. Cis- and trans-acting IncRNAs in pluripotency and reprogramming. Curr Opin Genet Dev. 2017:46:170-8.

102. Agliano F, Rathinam VA, Medvedev AE, Vanaja SK, Vella AT. Long noncoding RNAs in host-pathogen interactions. Trends Immunol. 2019:40:492-510.

103. Zhan J, Chitta RK, Harwood FC, Grosveld GC. Phosphorylation of TSC2 by PKC- $\delta$ reveals a novel signaling pathway that couples protein synthesis to mTORC1 activity. Mol Cell Biochem. 2019;456:123-34.

104. Wang Y, Zhao H, Shao Y, Liu J, Li J, Xing M. Interplay between elemental imbalance-related PI3K/Akt/mTOR-regulated apoptosis and autophagy in arsenic (III)-induced jejunum toxicity of chicken. Environ Sci Pollut Res Int. 2018;25:18662-72.

105. Kogut MH, Genovese KJ, He H, Arsenault RJ. AMPK and mTOR: sensors and regulators of immunometabolic changes during Salmonella infection in the chicken. Poult Sci. 2016;95:345-53.

106. Zhang S, Wu W, Wu Y, Zheng J, Suo T, Tang H, et al. RNF152, a novel lysosome localized E3 ligase with pro-apoptotic activities. Protein Cell. 2010;1:656-63.

107. Damdinsuren B, Nagano H, Wada H, Noda T, Natsag J, Marubashi S, et al. Interferon alpha receptors are important for antiproliferative effect of interferon-alpha against human hepatocellular carcinoma cells. Hepatol Res. 2007:37:77-83.

108. Zhang L, Li H, Chen Y, Gao X, Lu Z, Gao L, et al. The down-regulation of casein kinase 1 alpha as a host defense response against infectious bursal disease virus infection. Virology. 2017;512:211-21.

109. Zhang K, Han Y, Zhao Y, Sun Y, Zou M, Fu Y, et al. Upregulated ggamiR-16-5p inhibits the proliferation cycle and promotes the apoptosis of MG-infected DF-1 cells by repressing PIK3R1-mediated the PI3K Akt/NF-KB pathway to exert anti-inflammatory effect. Int J Mol Sci. 2019;20:1036.

110. Brumlik MJ, Pandeswara S, Ludwig SM, Murthy K, Curiel TJ. Parasite mitogen-activated protein kinases as drug discovery targets to treat human protozoan pathogens. J Signal Transduct. 2011;2011:971968

111. Wei F, Wang W, Liu Q. Protein kinases of Toxoplasma gondii: functions and drug targets. Parasitol Res. 2013;112:2121-9.

112. Bussière Fl, Brossier F, Le Vern Y, Niepceron A, Silvestre A, de Sablet T, et al. Reduced parasite motility and micronemal protein secretion by a p38 MAPK inhibitor leads to a severe impairment of cell invasion by the apicomplexan parasite Eimeria tenella. PLoS ONE. 2015;10:e0116509. 
113. Kitessa SM, Nattrass GS, Forder RE, McGrice HA, Wu SB, Hughes RJ. Mucin gene mRNA levels in broilers challenged with Eimeria and/or Clostridium perfringens. Avian Dis. 2014;58:408-14.

114. Koonen DP, Glatz JF, Bonen A, Luiken JJ. Long-chain fatty acid uptake and FAT/CD36 translocation in heart and skeletal muscle. Biochim Biophys Acta. 2005;1736:163-80

115. Nicholls HT, Kowalski G, Kennedy DJ, Risis S, Zaffino LA, Watson N, et al. Hematopoietic cell-restricted deletion of CD36 reduces high-fat diet-induced macrophage infiltration and improves insulin signaling in adipose tissue. Diabetes. 2011;60:1100-10.

116. Harb D, Bujold K, Febbraio M, Sirois MG, Ong H, Marleau S. The role of the scavenger receptor $\mathrm{CD} 36$ in regulating mononuclear phagocyte trafficking to atherosclerotic lesions and vascular inflammation. Cardiovasc Res. 2009;83:42-51.

117. Stewart CR, Stuart LM, Wilkinson K, van Gils JM, Deng J, Halle A, et al. CD36 ligands promote sterile inflammation through assembly of a tolllike receptor 4 and 6 heterodimer. Nat Immunol. 2010;11:155-61.

118. Xie J, Wang M, Cheng A, Zhao XX, Liu M, Zhu D, et al. DHAV-1 inhibits type I interferon signaling to assist viral adaption by increasing the expression of SOCS3. Front Immunol. 2019:10:731.

119. Lillehoj HS. Role of T lymphocytes and cytokines in coccidiosis. Int J Parasitol. 1998;28:1071-81.

120. Kundu K, Garg R, Kumar S, Mandal M, Tomley FM, Blake DP, et al. Humoral and cytokine response elicited during immunisation with recombinant immune mapped protein-1 (EtIMP-1) and oocysts of Eimeria tenella. Vet Parasitol. 2017;244:44-53.

121. Allen PC. Physiological responses of chicken gut tissue to coccidial infection: comparative effects of Eimeria acervulina and Eimeria mitis on mucosal mass, carotenoid content, and brush border enzyme activity. Poult Sci. 1987;66:1306-15.

122. Ebbesen KK, Kjems J, Hansen TB. Circular RNAs: identification, biogenesis and function. Biochim Biophys Acta. 2016;1859:163-8.

123. $\mathrm{Xu} Z$ Z, Li P, Fan L, Wu M. The potential role of circRNA in tumor immunity regulation and immunotherapy. Front Immunol. 2018;9:9.

124. Jeck WR, Sharpless NE. Detecting and characterizing circular RNAs. Nat Biotechnol. 2014:32:453-61.

125. Guo JU, Agarwal V, Guo H, Bartel DP. Expanded identification and characterization of mammalian circular RNAs. Genome Biol. 2014;15:409.

126. Abdelmohsen K, Panda AC, Munk R, Grammatikakis I, Dudekula DB, De $S$, et al. Identification of HuR target circular RNAs uncovers suppression of PABPN1 translation by CircPABPN1. RNA Biol. 2017;14:361-9.

\section{Publisher's Note}

Springer Nature remains neutral with regard to jurisdictional claims in published maps and institutional affiliations.
Ready to submit your research? Choose BMC and benefit from:

- fast, convenient online submission

- thorough peer review by experienced researchers in your field

- rapid publication on acceptance

- support for research data, including large and complex data types

- gold Open Access which fosters wider collaboration and increased citations

- maximum visibility for your research: over 100M website views per year

At BMC, research is always in progress.

Learn more biomedcentral.com/submissions 